\title{
Temperament theory and the study of cognition-emotion interactions across development
}

\author{
Heather A. Henderson ${ }^{\mathrm{a}, *}$, Theodore D. Wachs ${ }^{\mathrm{b}}$ \\ a Department of Psychology, University of Miami, Coral Gables, FL, USA \\ ${ }^{\mathrm{b}}$ Department of Psychological Sciences, Purdue University, West Lafayette, IN, USA
}

Available online 1 August 2007

\begin{abstract}
In this paper we review current definitions and measurement approaches used to assess individual differences in children's temperament. We review the neural bases of temperamental reactivity and self-regulation and propose that these constructs provide a framework for examining individual differences and developmental change in emotion-cognition interactions across development. Studies are reviewed in which some well-documented contextual effects on the expression of temperament can be interpreted in terms of the influence of biological and non-biological factors on CNS functioning. We conclude with ideas regarding future directions for the study of individual differences and developmental change in cognition-emotion interactions as they are shaped throughout development. (C) 2007 Elsevier Inc. All rights reserved.
\end{abstract}

Keywords: Temperament; Reactivity; Self-regulation; Approach/withdrawal; Effortful control; CNS; fMRI; EEG/ERP

There is a burgeoning literature on the neural correlates of developmental change and individual differences in numerous aspects of cognition and emotion. These rapid advances reflect a growing recognition of the utility of cross-disciplinary approaches for studying development, as well as the availability of new methodologies that provide developmental psychologists with the opportunity to directly assess the neural correlates of behavior. Although theory and research related to cognitive and emotional development have tended to proceed in parallel, new measurement approaches and collaborative efforts serve as a reminder of the importance of considering the simultaneous and interdependent

\footnotetext{
* Corresponding author. Fax: +1 3052844795.

E-mail address: h.henderson@miami.edu (H.A. Henderson).
} 
nature of growth in the two domains. Our focus in this review is on biological contributions to the development of individual differences in temperament, with specific reference to the central nervous system (CNS). We regard temperament as a model area of study in which questions related to cognition-emotion interactions and their implications for development can be explicitly addressed. Rothbart's (1991) theory, which postulates two major dimensions of temperament, reactivity and self-regulation, will be used to illustrate the interplays between cognition and emotion. We believe that the integration of two largely independent fields of research, temperament and developmental cognitive neuroscience, will lead to conceptual and empirical advances in our understanding of the neural bases of individual and developmental differences in the dynamic interplay of cognition and emotion throughout childhood and adolescence.

Although the conceptual roots of temperament can be traced back over 2000 years, much of the current scientific interest in temperament has a more recent history, dating to the initial publication of results from Thomas and Chess' New York Longitudinal Study (NYLS - Thomas, Chess, Birch, Hertzig, \& Korn, 1963). Following the initial publications from this study, there has been increasing interest in temperament by developmental researchers (see Kohnstamm, 1989). Support for this assertion comes from a search on PsychInfo from 1967 to the present, entering the word temperament and restricting the search to human research published in English. Between 1967 and 1976 there were 248 articles listed involving temperament. The number of articles listed involving temperament has increased each decade with over 2700 articles listed in the period from 1997 to 2006. This increasing interest in temperament as an area of study reflects increasing appreciation that individual differences in early temperament may be a necessary precursor for later individual differences in personality (Caspi, 1998; Halverson, Kohnstamm, \& Martin, 1994), behavioral adjustment (Bates, 2001; Guerin, Gottfried, Oliver, \& Thomas, 2003), cognition (Hongwanishkul, Happaney, Lee, \& Zelazo, 2005), academic success (Guerin et al., 2003; Posner \& Rothbart, 2007), and the nature of parent-child transactions (Putnam, Sanson, \& Rothbart, 2002; Wachs, 2006).

This review is divided into four sections. First, we present current definitions and measurement approaches used to assess individual differences in children's temperament. Second, we review the research literature on the neural bases of emotional reactivity and the cognitive (e.g., attentional) processes underlying self-regulation, as well as possible interactions between reactivity and self-regulation. Third, we discuss contextual effects on the expression of temperament and illustrate how these effects can operate through temperament-related CNS functions. We conclude with ideas regarding future directions for studying the neural bases of temperament and associated cognition-emotion interactions as they develop over childhood.

\section{The nature of temperament}

\section{Definitional issues}

We begin our review by discussing what is meant by the term temperament, and how our conceptualization of temperament relates to our understanding of the neural contributions to the behavioral characteristics that define temperament.

Similar to what is found for the concept of intelligence, multiple definitions of temperament currently co-exist. Also similar to the concept of intelligence there exists a "working 
definition" of temperament that would be accepted by a large majority of temperament researchers and theorists namely: "Biologically rooted individual differences in behavior tendencies that are present early in life and are relatively stable across various kinds of situations and over the course of time" (Bates, 1989, p. 4). It has been suggested that individual differences in infant temperament can be viewed as the early expression of personality traits, with particular reference to the "big 5" personality dimensions (Halverson et al., 1994). While there are some conceptual and empirical linkages between temperament and personality dimensions (Hagekull \& Bohlin, 1998; Rothbart, Ahadi, \& Evans, 2000) there are also some critical distinctions. While temperament may provide the foundations for the later emergence of personality, temperament per se does not include complex processes such as attributions, self-concept, or conscious self-presentation concerns that are central to the expression of personality. Rather, as will be discussed below, the core concepts in temperament focus around individual differences in reactivity and selfregulation. While our primary focus in this chapter will be on the biological roots of temperament, with specific reference to central nervous system (CNS) structures and processes, each aspect of this definition deserves some discussion.

\section{Early appearing}

Most researchers interested in the study of temperament have focused on individual differences starting around 3 months of life. However, implicit in the definition of temperament is the assumption that we should be able to identify individual differences in at least some domains of temperament in newborns (Rothbart, Derryberry, \& Posner, 1994) and perhaps even prenatally (DiPietro et al., 2002; DiPietro, Hodgson, Costigan, \& Johnson, 1996). While identifying stable individual behavioral characteristics prenatally or in newborns is an enterprise fraught with methodological perils, researchers have been able to classify a number of neonatal behavioral patterns in terms of known temperament dimensions, including negative emotionality, soothability and alertness (Matheny, Riese, \& Wilson, 1985; St. James Roberts \& Wolke, 1988; Wachs, Pollitt, Cueto, \& Jacoby, 2004). Of particular relevance to this chapter is the hypothesis that changes in the characteristics of neonatal temperament across the first several months of life may be linked to developmental changes in the CNS (Rothbart, Derryberry, \& Hershey, 2000).

\section{Relatively stable}

Based on earlier evidence stressing the genetically driven nature of individual differences in temperament (e.g., Wilson \& Matheny, 1983), a logical assumption was that individual differences in temperament should be stable over time and across contexts. Without denying the importance of genetic influences this assumption is becoming increasingly questionable, given evidence for the effects of contextual factors on the expression of individual differences in temperament (Wachs \& Kohnstamm, 2001), including the trainability of attention processes related to self-regulation (Rueda, Rothbart, McCandliss, Saccamanno, \& Posner, 2005). In addition, recent models of gene action illustrate how different gene systems can turn on or turn off at different points in development (e.g., Gottlieb, 2003). Given this pattern of findings, it is now more logical to expect only modest stability of temperament across different contexts and over time. For the most part, this latter expectation has been confirmed with test-retest correlations in the range of .40-.60 
(e.g., Guerin et al., 2003; Pedlow, Sanson, Prior, \& Oberklaid, 1993; Rothbart, Ahadi, Hershey, \& Fisher, 2001).

With regard to context, we would expect to find greater stability in child temperament patterns within a given situation than across situations. Supporting this hypothesis is evidence showing that agreement between mother and father ratings of their child's temperament are consistently higher than agreements between mother and teacher (Goldsmith, 1996). The most likely explanation of this finding is that the child's temperament is expressed in somewhat different ways at home versus school. Similarly, even highly inhibited children may react in the same way as less inhibited children when the situation is familiar and comfortable to the child. It is only in unfamiliar situations that we see differences between more and less inhibited children (Gunnar, 1994).

Based on parent report measures, moderate stability of individual temperament dimensions across time appears to be the norm (Guerin et al., 2003; Kerr, Lambert, Stattin, \& Klackenberg-Larsson, 1994; Rothbart et al., 2000), with increasing stability after 2 years of age (Lemery, Goldsmith, Klinnert, \& Mrazek, 1999; Pfeifer, Goldsmith, Davidson, \& Rickman, 2002). A similar pattern of findings occurs when laboratory assessments of temperament are utilized, with results again indicating both moderate cross-temporal stability of child temperament (Matheny \& Phillips, 2001; Rothbart et al., 2000) and greater stability after 24 months of age (Kochanska, 2001). This finding of moderate cross-time stability occurs even when extreme groups are utilized. For example, Fox, Henderson, Rubin, Calkins, and Schmidt (2001) reported that only $50 \%$ of children who had been characterized as highly inhibited, based on their extreme reactions to novelty as infants, maintained a profile of social withdrawal and reticence continuously until the preschool years. Similarly, Pfeifer et al. (2002) reported that $75 \%$ of children who had been classified as extremely inhibited as toddlers were not in the extreme inhibition group at 7 years of age, while over $80 \%$ of toddlers who were classified as extremely uninhibited were no longer classified in this way at 7 years. While the results from studies of children with extreme temperaments do indicate a shift in temperament over time, what these studies also show is that it is very rare for children at one extreme to shift to the other extreme. Extremely inhibited children rarely become uninhibited; rather, these children shift toward the middle of the distribution becoming less inhibited over time. Similarly, extremely uninhibited children rarely become inhibited; rather these children become less uninhibited over time. This restricted range of change for children with extreme temperament is consistent with the conclusion that temperament is moderately stable.

Based on studies involving both context and time, temperament is currently viewed as a predisposing set of individual characteristics with the potential to systematically change over time as the child develops, and for individual differences in temperament to be manifested in different ways in response to the nature of the context within which the individual is functioning (Wachs, 2006). As noted earlier, changes in temperament over time may reflect systematic changes in CNS structure and processes (Rothbart, Ahadi, \& Hershey, 1994). Context related changes in the expression of temperament may be difficult to link to changes in CNS structure. However, there is evidence that individual differences in temperament may be influenced by neurotransmitter activity, with the few published studies directly assessing these associations focusing on the serotonin and dopamine systems (e.g., Auerbach et al., 1999; Lakatos et al., 2003; Posner, Rothbart, \& Sheese, 2007). However, the overwhelming majority of this evidence is based primarily on studies with infrahuman samples and human adults (Reif \& Lesch, 2003). The fact that temperament 
appears early in life emphasizes the need for research on neurotransmitter contributions to temperament in infancy and childhood. Evidence also indicates that either neurotransmitter activity (Rogeness \& McClure, 1996) or the physiological systems that can influence neurotransmitter activity are sensitive to contextual characteristics (e.g., neurohormonal systems: Gunnar, 2000). The overall pattern of findings suggests that context driven changes in temperament may be mediated by context driven changes in neurotransmitter metabolism.

\section{Behavior tendencies}

There still remains disagreement about which specific behavioral characteristics fall under the domain of temperament. In part this may reflect that fact that certain individual characteristics such as activity level, persistence, attentional flexibility and attentional control also fit the definitional criteria used to define other behavioral domains such as motivation and cognition (Wachs, 2006). While this categorical overlap may be purely semantic, there also is the possibility that linkages between different areas of the CNS may result in non-temperament functions influencing the expression of individual differences in temperament. Alternatively, there is the possibility that our neat division of individual characteristics into specific domains such as temperament, emotion, cognition, or motivation is overly simplistic given the dynamic nature of the neural contributions to these domains of development (Steinmetz, 1994).

Going beyond individual behavioral characteristics, there also is increasing agreement that the various behaviors thought to define individual differences in temperament fall into one of two major domains: reactivity and self-regulation (Rothbart \& Bates, 2006). Reactivity refers to the speed, strength and valence (positive or negative) of an individual's characteristic responses to stimulation. Examples of behaviors that would characterize reactivity could include how quickly infants react to a noxious stimulus such as their arms being restrained, or whether a child's emotional response to a novel object is positive or negative in nature. Negative reactivity can be further subdivided into anger (e.g., distress to limits) and fear (e.g., distress to novelty-Rothbart \& Derryberry, 1981; Rothbart et al., 2000).

Self-regulation refers to the behaviors the individual uses to control their behavioral and emotional reactions to sources of both positive and negative stimulation. Even young infants can regulate their degree of distress reactivity by directing attention away from fear inducing objects or by sucking their fingers to distract themselves. The behavioral strategies infants use for self-regulation are, in part, age dependent. The earliest appearing form of self-regulation is reactive control, which involves involuntary tendencies to avoid negative stimulation, approach positive stimuli, and reorient away from overly intense positive stimulation (Derryberry \& Rothbart, 1997). Active self-regulation, which involves voluntary attentional control and the ability to inhibit ongoing behavior, appears later in development starting towards the end of the second year (Derryberry \& Rothbart, 1997; Eisenberg, 2002). Conceptually, it is the interaction between different levels of reactivity and self-regulation that acts to guide temperament driven behavior for each individual child (Belsky, Friedman, \& Hsieh, 2001; Eisenberg et al., 2001, 2004; Stifter, Spinrad, \& Braungart-Rieker, 1999).

One major advantage of conceptualizing temperament on the basis of individual differences in reactivity and self-regulation is that this conceptual scheme fits very nicely with a number of brain-behavior models. One such model is seen in the conceptual framework 
defined by Gray (1991), which includes a behavioral approach or activation system that responds to cues of potential reward or termination of punishment, and a behavioral inhibition or anxiety system that responds to cues for punishment or non-reward. Discussion of these systems and their relation to the development of individual differences in temperament will be elaborated upon in later sections of this review. A second major advantage of conceptualizing temperament within a reactivity/self-regulation framework is that such a framework fits well with current knowledge of CNS development. For example, the appearance of active self-regulation strategies towards the end of the second year of life maps on to developmental changes in those portions of the brain which are involved in executive control of attention (Rothbart \& Bates, 2006). Elaboration of links between CNS changes and the changing nature of temperament over time will also be elaborated in subsequent sections of this review.

\section{Temperament as biologically rooted}

Historically, temperament has always been viewed in biological terms. In early conceptualizations, the biological contributions to individual differences in temperament related mood states were viewed in relation to the balance between different bodily humors (Diamond, 1974). Of almost equal antiquity is the linking of temperament to body type (Rothbart, 1989), with this linkage carrying over into the middle part of the previous century (e.g., Sheldon \& Stevens, 1942). With the rise of phrenology, 19th century scholars began to increasingly focus on the brain as the organ most critical for understanding individual differences in temperament (e.g., Jacques, 1881). This linking of brain and temperament was carried on in a more scientific fashion by researchers working within a Pavlovian framework (Strelau, 1989). More recently, the study of the biological roots of temperament has taken on a more genetic flavor, encompassing both behavioral genetic (e.g., Saudino, 2005; Wilson \& Matheny, 1983) and molecular genetic studies (Auerbach et al., 1999; Plomin \& Rutter, 1998).

Bates (1989) has suggested that the biological bases of temperament can be conceptualized in two ways. First, there are patterns of "neurological individuality." These patterns of neurological individuality reflect CNS contributions to temperament and are the main focus of this review. Although the CNS also regulates autonomic nervous system and hormonal functions related to temperament, such as vagal tone, which is associated with negative emotionality and soothability (Huffman et al., 1998), and the secretion of prolactin which is related to negative emotionality (Lozoff et al., 1995), our focus here is on central nervous system structures and function directly related to temperament. Second, there are biologically based influences upon neurological individuality such as genetics, which will also be considered in a later section in this review.

\section{The measurement of individual differences in temperament}

This review would be incomplete without at a brief discussion on how temperament is measured and the implications of different measurement strategies for understanding neural contributions to the development of individual differences in temperament. Four approaches to assessing individual differences in early temperament have been developed: (1) Structured or semi-structured clinical interviews of parents, (2) Direct observations of infant behavior in unstructured, naturalistic contexts; (3) Parent or caregiver responses to 
questionnaires; (4) Laboratory based observation of infant behavior in structured situations. While parent interview procedures were the basis of the ground breaking New York Longitudinal Study (Thomas et al., 1963), for the most part, such procedures have been less often used in recent years. Likewise, although unstructured observational procedures have been used for assessing temperament in the neonatal period (e.g., Ricciuti \& Breitmayer, 1988) and with older infants and toddlers (e.g., Bornstein, Gaughran, \& Segui, 1991), and mechanical devices such as actometers have been used to assess children's naturally occurring activity levels (e.g., Eaton \& Dureski, 1986), there has been relatively little systematic development of unstructured observational approaches. Further, unstructured naturalistic assessments of temperament may be incompatible with many of the current neural assessment techniques being utilized, which require controlled laboratory conditions or the avoidance of extraneous movements (Posner, Rothbart, \& Gerardi-Caulton, 2001). Parent report measures are the most frequently used procedure for assessing individual differences in temperament. In part, this is due to a number of clear advantages of parent report measures including ease of administration and built in aggregation, since caregivers usually base their ratings on experience with their child on repeated occasions and across different contexts. However, parent report measures have also been criticized for assessing parental emotional characteristics, such as anxiety and depression or parental expectancies about their child rather than child characteristics (Goldsmith \& Hewitt, 2003; Mebert, 1991; Seifer, Sameroff, Barrett, \& Krafchuk, 1994; Vaughn, Taraldson, Crichton, \& Egeland, 1981). While parent report measures do contain some subjective parental components, available evidence indicates that these measures also contain a substantial objective component that does accurately assess children's individual characteristics (Wachs \& Bates, 2001). While some parent report measures such as the Toddler Behavior Assessment Questionnaire (TBAQ - Goldsmith, 1996) were derived from a psychobiological rather then a clinical perspective, and thus tap dimensions of temperament which may have more direct links to neural function, such measures would not be our first choice in research on the neural underpinnings of temperament. This is because parent report measures, however valid, still assess parent perceptions of child temperament. To the extent that neural characteristics directly impact upon children's temperament-related behavioral patterns in real time, a more direct measurement of ongoing behavior seems preferable.

Currently there are several validated, structured, laboratory based temperament assessment procedures including the LAB-TAB (Goldsmith \& Rothbart, 1996) and the Louisville Temperament Assessment Battery (Matheny, 1991). Typically these assessment procedures are based on presenting a series of structured situations to infants or toddlers and videotaping and then coding their reactions to these situations along specific temperament dimensions. Structured laboratory based temperament assessments appear to be methodologically compatible with neural assessment procedures, especially with regard to assessing both neural processes and behavioral reactions associated with time linked specific events or situations presented to the infant. However, researchers should also recognize some of the constraints associated with deriving temperament scores from laboratory assessment (Henderson \& Fox, 2007; Wachs \& Bates, 2001). One such constraint is the degree to which the child's behavior during a single laboratory assessment is representative of the child's actual temperament patterns occurring in different situations. While relatively few comparisons have been made between laboratory and parent report assessments, what evidence is available does suggest moderate correlations on the same 
dimensions across these two data sources (Rothbart et al., 2000). While such results are encouraging, far more supportive evidence is needed on the questions of how representative laboratory assessments are of the child's temperament and whether there is equal representativeness of all dimensions of temperament assessed in a laboratory setting. Over and above the issue of representativeness of laboratory assessments, there are other constraints that may be operating. These include limits in accurately coding what may be relatively subtle behavioral changes, effects of unmeasured caregiver-child interactions or other experiences occurring in the period before the child enters the laboratory situation, constraints on the range of stimuli that can be presented to the child and the problem of repeated testing effects if repeated laboratory testing sessions are utilized.

Although relatively brief, it is hoped that this discussion of measurement of temperament alerts neuroscience researchers to the importance of using precise and valid measures not just of neural function, but also of behavior. While the new generation of neural assessments has led to dramatic findings about how the CNS operates, even state of the art brain assessments will tell us little about the neural roots of individual differences in temperament if neural assessments procedures are paired with less valid or inappropriate assessments of temperament. As one approach to maximizing validity of temperament assessments, reviewers have suggested assessing temperament at the same point in time using different assessment procedures, and then aggregating measurements across common temperament dimensions (Rothbart \& Bates, 2006; Wachs \& Bates, 2001). For example, aggregating parent report and laboratory assessments of children's negative emotionality or inhibition minimizes the measurement problems found if we relied just on parent report or just on laboratory measures of these temperament traits.

\section{The neural bases of temperament}

As noted earlier there is a long history of speculation regarding the physiological bases of individual differences in temperament and personality. One of the earliest descriptions of temperament was the Hippocrates-Galen typology in which four personality types (melancholic, choleric, sanguine, and phlegmatic) were related to the balance of bodily humors within an individual. The sanguine personality was characterized as optimal due to the perfect balance of bodily humors, while the other three types were viewed as less than optimal due to a predominance of one humor over the others (see Kagan, 1994; Strelau, 1983). Centuries later, Pavlov and his students developed detailed theoretical models relating the strength or integrity of the central nervous system to individual differences in motivation and emotion, noting the similarities between their own nervous system typologies and those of Galen. The work of Pavlov and his students provided the impetus for many empirical studies that together form the basis of several modern biologically-based theories of temperament and personality.

Three themes that were presented in the work of Pavlov and colleagues clearly foreshadowed current trends in the study of the neural bases of temperament and personality. First, Pavlov hypothesized that the balance of excitatory and inhibitory CNS processes within an individual determined their style for adapting to environmental demands and therefore their personality. Based on studies of the ease of conditioning, first in dogs and then in humans, Pavlov used the strength of excitation to refer to the working capacity or potential of cortical cells to react to environmental conditions. In contrast, inhibition referred to protective inhibition, which functioned to protect the CNS against overloading. 
The relative prominence of excitatory versus inhibitory processes was hypothesized to affect the efficiency, strength, and durability of conditioned reflexes, which in turn were hypothesized to predict individual differences in personality. The idea of an interplay between excitatory and inhibitory processes remains a theme in many temperament and personality models that center on the balance of opposing motivational states and/or the balance of reactive versus regulatory processes (e.g., Strelau, 1994).

Second, Pavlov and his students, most notably Krasnogorsky, discussed the interplay between excitatory processes in the cortex and excitatory processes in the subcortex, a theme that is paralleled in current discussions of the structural and functional interaction between cognition and emotion, also referred to as higher-order and lower-order processes, cold and hot systems, or controlled and automatic processes in modern research on temperament, personality, and individual differences (e.g., Metcalfe \& Mischel, 1999; Rothbart \& Derryberry, 1981; Satpute \& Lieberman, 2006). Finally, Krasnogorsky, unlike many of his colleagues, believed that CNS properties underlying temperament and personality could be influenced by contextual factors including learning experiences, nutrition, and disease, an idea that foreshadowed current research evidence on biological and non-biological factors influencing the structural and functional development of temperament related CNS structures and processes (Wachs, 2006).

Although Pavlov's general model provided the foundation for much work on the biological bases of temperament, the focus was on functional rather than neurophysiological or biochemical aspects of CNS processes. As such, CNS properties in relation to temperament were originally described in a general way as though they applied equally across the entire brain (see Kagan, 1998). The technological advances of the last quarter century have allowed these early ideas to be greatly refined by identifying neural regions and processes that function together to govern motivational and emotional processing. In the following sections, the three themes originating from Pavlov's studies are revisited in the context of current theory and empirical studies relating CNS functioning to temperament and social development. Specifically, the relations between CNS functioning and individual differences in reactive and self-regulatory aspects of temperament are reviewed. Next, recent neuroimaging studies assessing interactions of subcortical emotional reactions and cortical cognitive processes are examined and discussed in terms of the simultaneous activation of reactive and self-regulatory processes. In the final section, contextual effects on the development of temperament-related CNS functioning are discussed.

\section{The CNS and temperamental reactivity}

Most models of temperament and personality include a dimension or factor that describes reactions to stimuli in terms of the extent to which positive affect and approach behaviors versus negative affect and avoidance/inhibition behaviors are elicited (e.g., Cloninger, 1987; Depue \& Iacono, 1989; Eysenck, 1967; Gray, 1991; Thomas \& Chess, 1977). Davidson and colleagues organize their model of personality and emotion around this approach/withdrawal construct; however, they contend that these reactions reflect the functioning of two relatively independent neural systems (e.g., Davidson, 1993; Davidson, 1998a). Specifically, Davidson and others have identified two circuits of inter-related brain regions that function to support emotion, affective style, and emotion regulation (Heller, Koven, \& Miller, 2003; Jackson et al., 2003; Urry et al., 2006). Support for the notion that there are two systems governing approach and withdrawal reactions comes from findings 
showing that (1) these reactions are regulated by different brain mechanisms and (2) the degree of association between approach versus withdrawal motivations varies across individuals.

Approach or appetitive motivations have been hypothesized to be governed by the behavioral approach (or activation) system (BAS) that is responsive to signals of reward and the termination or omission of punishment. BAS activation facilitates behavior that brings an individual into closer proximity to desired goals and in the presence of cues of impending rewards, the BAS creates positive feelings. In contrast, the behavioral inhibition system (BIS) is responsive to signals of punishment, nonreward, and novelty and elicits behavioral inhibition or the interruption of an ongoing behavior, and an associated increase in arousal and vigilance. The behaviors elicited by the BIS function to maintain or increase the proximity of an individual to the eliciting stimulus. Activation of the BIS in response to cues of potential punishment or novelty underlies the subjective states of fear and anxiety (Gray, 1991).

The most parsimonious interpretation of BIS/BAS tendencies is that they represent biases towards different motivational states rather than biases towards experiencing negatively versus positively valenced emotions. This interpretation arises primarily from findings showing that BAS activation can in fact lead to the expression of a variety of negative emotions. While BAS reactions tend to be thought of as positive in valence (i.e., happiness, excitement), when an individual is highly motivated towards a goal and that goal is blocked, negative emotions, particularly anger and frustration, are elicited (Carver, 2004; Harmon-Jones, 2003; Harmon-Jones \& Allen, 1998). As such, BIS/BAS tendencies are best considered as motivational tendencies as opposed to biases towards positive versus negative emotional states per se.

As was the case in Pavlov's early work, individual differences in temperament reaction tendencies are often conceptualized in terms of the relative balance of approach versus withdrawal tendencies within an individual. For example, highly sociable and gregarious personalities could be described as being high in BAS activity and low in BIS activity, whereas fearful, withdrawn, and introverted personalities could be described as high in BIS and low in BAS. In relation to Rothbart's model of child temperament, BIS/BAS characteristics are captured in a variety of dimensions subsumed under the broader construct of temperamental reactivity. In this model, reactivity is defined as the threshold, intensity, and duration of reactions to stimulus conditions which can be measured in terms of the onset, duration, and intensity of emotional expressions (Rothbart \& Bates, 2006; Rothbart \& Derryberry, 1981).

Based on factor analytic studies of parent ratings of child temperament, Rothbart and colleagues have identified and replicated two higher-order factors that describe individual differences in temperamental reactivity: Surgency and Negative Affectivity. Surgency is defined by dimensions of approach, high-intensity pleasure (or sensation seeking), activity level, and a negative loading of shyness (Ahadi, Rothbart, \& Ye, 1993). Thus, children who are rated as high in Surgency could be described as being relatively high in BAS and low in BIS motivations while children who are rated low in Surgency could be described as being relatively low in BAS and high in BIS motivations. The emotional consequences of both BIS and BAS motivational states (i.e., fear for BIS and anger/sadness for BAS) are captured in a second temperament factor called Negative Affectivity. In Rothbart's temperament model, the Negative Affectivity factor is defined by scales of discomfort, fear, anger/frustration, sadness, and a negative loading of soothability (Ahadi 
et al., 1993; Rothbart et al., 2001). Thus, children high in either BAS or BIS could be expected to be relatively high in Negative Affectivity (see Fig. 1). The correlation between the Surgency and Negative Affectivity factors tends to be close to zero, suggesting that they are relatively orthogonal (Rothbart et al., 2001). These higher-order factors and their inclusion of motivational states and emotional reactions characteristic of the BIS/BAS system are comparable to those identified in other models of temperament including Sanson and colleagues' factors of approach and negative emotionality identified in the Australian Temperament Project (Sanson, Prior, Garino, Oberklaid, \& Sewell, 1987), and the approach/withdrawal and negative reactivity factors identified in the Middle Childhood Temperament Questionnaire (MCTQ), a questionnaire based on the original dimensions described by Thomas and Chess in the NYLS (Hegvik, McDevitt, \& Carey, 1982; McClowry, Hegvik, \& Teglasi, 1993).

In the sections below, the CNS structures and functions underlying BIS/BAS reactions will be reviewed as well as empirical studies relating these CNS structures to individual differences in BIS/BAS characteristics of personality and temperament.

\section{The neuroanatomy of approach/withdrawal reactions}

Gray (1975) identified a set of inter-related neural structures underlying BIS reactions that include the ascending reticular activating system, orbital frontal cortex, medial septal area, and hippocampus. Specifically, Gray described a feedback loop in which the ascending reticular activating system responds to signals of punishment and nonreward by activating the medial septal area, which in turn stimulates the hippocampus, resulting in the inhibition of reticular activity and therefore ongoing behavior. Davis (1992) expanded this network to emphasize the central role of the amygdala in the elicitation of fear and anxiety. Specifically, Davis described the mediating role of the central nucleus of the amygdala in fear or anxiety responses based on the extensive connections between the central nucleus and the orbital frontal cortex, other amygdala nuclei, bed nucleus of stria terminalis, lateral hypothalamus, central gray midbrain region, and brainstem nuclei. By assigning a central role to the amygdala and the connections between the amygdala and brainstem nuclei governing autonomic and motor responding, this expanded circuit accounts for

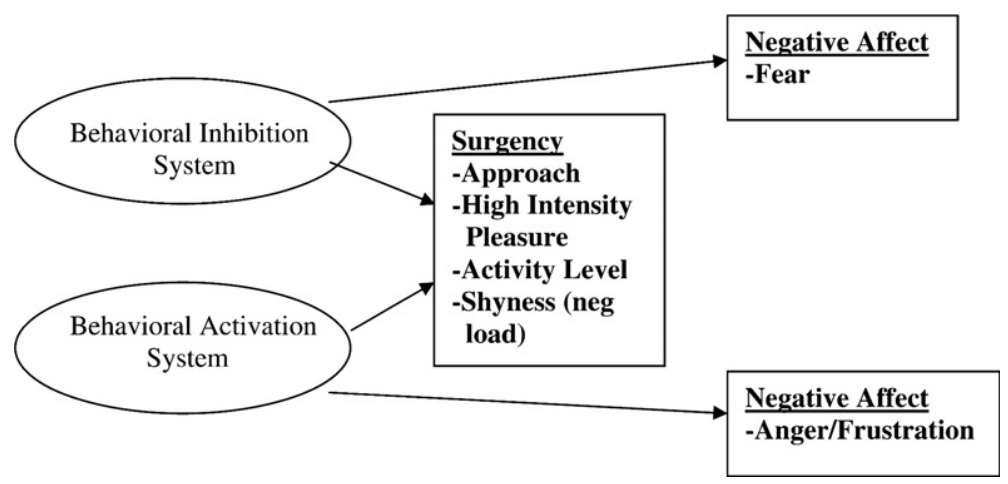

Fig. 1. Schematic depiction of the associations between the behavioral inhibition and behavioral activation systems and Rothbart's temperament factors, surgency and negative affect. The dashed line indicates an inverse association. 
many of the universal fear reactions expressed by mammals, including autonomic arousal and motor inhibition.

Much of the empirical work examining the associations between behavioral and neural aspects of BIS functioning has focused on the role of the amygdala in fear responses. In a series of studies with non-human animals, LeDoux (1987) demonstrated the central role of the amygdala in the acquisition of conditioned fear reactions and the learning of new stimulus-threat contingencies. The amygdala appears to function in the creation of conditioned fear responses by assigning affective significance, particularly of negative valence, during both sensory and cognitive information processing (see LeDoux, 1987, or review). In support of this argument, several fMRI studies with young adults demonstrate bilateral amygdala activation in response to negatively-valenced stimuli (i.e., pictures of aversive stimuli or fearful faces) but not neutral stimuli (e.g., Canli, Sivers, Whitfield, Gotlib, \& Gabrieli, 2002; Irwin et al., 1996; Whalen et al., 1998). Similarly, when asked to view an angry or fearful face and match the expression to a simultaneously presented face, healthy adults show an increase in regional cerebral blood flow bilaterally in the amygdala (Hariri, Bookheimer, \& Mazziotta, 2000). While adolescents also show bilateral amygdala activation while viewing fearful faces (Baird et al., 1999), the amygdala responses of children appear to be less specific to fearful stimuli. Thomas et al. (2001) found that young adults, but not children, showed increased left amygdala activation while viewing fearful faces in a passive viewing paradigm. In fact, children showed greater bilateral amygdala activation while viewing neutral versus fearful faces. Thomas et al. suggest that for children, neutral facial expressions may be perceived as more ambiguous than fearful expressions and therefore elicit a state of vigilance via activation of the amygdala.

While amygdala activation in response to negatively-valenced and/or ambiguous stimuli appears to characterize a common affective information processing mechanism across individuals, individual differences in relatively stable temperamental traits have also been associated with differences in amygdala activity. Young adults who were previously identified as extremely inhibited and fearful versus uninhibited and exuberant in response to novelty as toddlers took part in an fMRI study in which they viewed a series of novel versus familiar faces. Those participants who had been previously identified as inhibited demonstrated significantly greater bilateral amygdala activation in response to novel, but emotionally neutral, faces compared to participants previously classified as uninhibited (Schwartz, Wright, Shin, Kagan, \& Rauch, 2003). Perez-Edgar et al. (2007) reported that adolescents who were consistently high in behavioral inhibition across childhood showed heightened amygdala activation when asked to rate their subjective fear states while viewing faces compared to adolescents who were consistently low in behavioral inhibition across childhood. Interestingly, this heightened activation was not specific to viewing fearful faces but generalized to other faces as well (angry, happy, neutral). In fact, the highest levels of activation were observed when behaviorally inhibited children were asked to rate their feelings of fear while viewing happy faces. Similar to the findings and interpretation of Thomas et al. (2001), this finding is interpreted as reflecting the sensitivity of the amygdala to ambiguity and uncertainty rather than fear per se. Functionally, this interpretation is consistent with descriptions of behaviorally inhibited children and adolescents as particularly sensitive to novelty, uncertainty, and ambiguity (Kagan, Reznick, Clarke, Snidman, \& Garcia-Coll, 1984; Kagan \& Snidman, 2004). Individual differences in amygdala activation also have been proposed as mediators of the association between serotonin 
transporter genes and individual differences in reactivity to stress and negative life events (Caspi et al., 2002; Fox et al., 2005; Hariri et al., 2002, 2005).

In contrast to the BIS, the BAS is sensitive to cues of impending reward and elicits behaviors that bring an individual into closer proximity to the reward. At a neural level, reward-relevant information is processed through cells in the orbitofrontal cortex, basolateral amygdala, lateral hypothalamus, and the nucleus accumbens of the ventral striatum (Berridge, 1996; Davidson, 1998a, 1998b; Depue \& Collins, 1999; Gray, 1991). The nucleus accumbens appears to be uniquely related to anticipatory reward-related responding. For example, during the anticipation of monetary rewards (but not punishments), adults show activation of the nucleus accumbens that increases in concert with increases in the magnitude of the anticipated reward (Knutson, Adams, Fong, \& Hommer, 2001). Importantly, the magnitude of nucleus accumbens activation correlated with self-reports of positive affect and happiness during reward anticipation (Knutson et al., 2001). Thus, the nucleus accumbens appears particularly critical in BAS responding in that it functions to assign affective significance, specifically positively valenced, during the processing of reward-relevant cues in the environment. While BAS neurocircuitry is hypothesized to relate to individual differences in temperamental surgency among young children, there are currently no neuroimaging studies that have examined this empirically.

\section{Temperamental differences in approach/withdrawal motivations and anterior EEG asymmetry}

Although neuroimaging studies are informative regarding the neural structures involved in motivation and emotion, many studies relating neural functioning to temperament and personality depend primarily on indirect measures such as resting EEG asymmetry. In Davidson's model of approach/withdrawal motivations and personality, approach/withdrawal tendencies are hypothesized to be lateralized in the anterior regions of the brain (Davidson, 1993; see also Fox, 1994; Silberman \& Weingartner, 1986). These hypotheses are based in part on the documented effects of unilateral lesions and strokes on emotional states such that left anterior damage tends to be associated with depressive symptoms and reduced positive affect (Morris, Robinson, Raphael, \& Hopwood, 1996) while right anterior damage is association with mania and dysregulated positive affect (Sackeim et al., 1982). Specifically, the left frontal region is hypothesized to be related to BAS reactions while the right frontal region is hypothesized to be related to BIS reactions. In accord with theoretical models of temperament and personality in which the relative balance of BIS/BAS tendencies is emphasized, measures of anterior asymmetry as an index of temperamental traits are computed by looking at the relative difference in EEG activation from left versus right anterior regions of the scalp.

The measurement of EEG has become popular as a tool for empirically examining psychobiological models of temperament and personality. Although a very gross measure of CNS functioning, the primary benefits for researchers, particularly those working with infants and young children, are the ease of collection and the noninvasive nature of EEG recordings. EEG can be recorded from the scalp using caps or nets containing large arrays of electrodes in predefined locations across the scalp. The variable of interest in most studies of temperamental reaction tendencies is alpha activity, which for adults is typically in the $8-13 \mathrm{~Hz}$ range and slightly lower in young children (Marshall, Bar Haim, \& Fox, 2002). Alpha desynchronization (i.e., reduced power in the alpha frequency band of the EEG) corresponds to increased cortical activity (see Davidson, Jackson, \& Larson, 
2000), so that EEG alpha power is greatest when an individual is alert but not actively processing stimuli (i.e., sitting quietly with eyes closed) and lowest when an individual is engaged in active processing (e.g., Davidson, Chapman, Chapman, \& Henriques, 1990; Parasuraman, Warm, \& See, 1998; Schaul, 1998). The asymmetry metric is typically a difference score in which the natural $\log (\ln )$ of left hemisphere alpha power is subtracted from the natural $\log (\ln )$ of the right hemisphere alpha power $(\ln ($ Right $)-\ln ($ Left $))$. A higher positive score on this index indicates greater alpha power in the right, which given the inverse association between power and activation, corresponds to less right or more left cortical activity. In contrast, a negative score on this index indicates greater right cortical activity. As such, positive scores are hypothesized to relate to heightened BAS reactivity while negative scores are hypothesized to relate to heightened BIS reactivity.

One assumption of studies linking frontal EEG asymmetry to motivational traits is that the asymmetry index is a stable trait of the individual. In support of this assumption, high levels of internal consistency (.80-.90) have been reported in several studies, based on collection periods ranging from 4 to $8 \mathrm{~min}$ in length (Hagemann, Ewald, Thayer, \& Bartussek, 2002; Hagemann, Hewig, Seifert, Naumann, \& Bartussek, 2005; Sutton \& Davidson, 1997). Test-retest correlations for resting asymmetry measures range from .50 to .60 for healthy young adults over a 2-6 week interval (e.g., Sutton \& Davidson, 1997; Tomarken, Davidson, Wheeler, \& Kinney, 1992) and were .66 for a sample of children assessed at 3-6 months and then again at 3 years of age (Jones, Field, Davalos, \& Pickens, 1997). Interestingly the stability values reported by Jones et al. (1997) are similar to the values found for parental report measures of infant and child temperament (Guerin et al., 2003; Pedlow et al., 1993; Rothbart et al., 2001).

Patterns of resting frontal asymmetry are thought to reflect a trait of the individual that serves as a diathesis for the risk of psychopathology. The diathesis appears to be mediated by the associations between patterns of resting asymmetries and an individual's BIS/BAS tendencies that characterize their emotional and behavioral reactions to eliciting conditions (Coan \& Allen, 2003; Davidson, 1998a; Henderson, Fox, \& Rubin, 2001). Studies with healthy young adults demonstrate associations between resting frontal EEG asymmetry and both trait and state measures of affective style. For example, Sutton and Davidson (1997) found that measures of resting anterior EEG asymmetry were related to participants' affective-motivational style as assessed using Carver and White's BIS/BAS self-report measure (Carver \& White, 1994). Specifically, relatively greater left frontal activation was positively correlated with BAS scores and greater BAS-BIS difference scores, whereas relatively greater right frontal activation was correlated with higher BIS scores. In addition, resting anterior asymmetries are related to the intensity of reaction that individuals report when viewing emotion-inducing stimuli such as short film clips. Specifically, Tomarken, Davidson, and Henriques (1990) reported that greater right frontal EEG activity was associated with self-reports of more intense negative affect after watching negatively valenced film clips, particularly those eliciting fear.

Similar findings have been reported in the literature on child temperament. Ten-monthold infants who cried during a brief separation from their mother showed greater baseline right frontal activation during an earlier baseline recording compared to infants who did not cry upon separation (Davidson \& Fox, 1989). Infants selected based on their strong behavioral reactions to unfamiliar stimuli at 4-months of age display greater right frontal activation at 9 months of age compared to infants who were either non-reactive or positively reactive to unfamiliarity (Calkins, Fox, \& Marshall, 1996). In the literature on 
behavioral inhibition, toddlers who show apprehensive and fearful reactions to unfamiliar social and nonsocial situations tend to show patterns of resting right frontal asymmetry (Calkins et al., 1996; Kagan, Reznick, \& Snidman, 1987). Patterns of right frontal EEG asymmetry are associated with tendencies to engage in solitary and non-social play when interacting with unfamiliar peers in preschoolers (Henderson, Marshall, Fox, \& Rubin, 2004). In addition, 7-year-old children who were rated high in temperamental shyness by their mothers showed greater increases in right frontal EEG activation compared to less shy children while performing a self-presentation task (Schmidt, Fox, Rubin, \& Sternberg, 1997). Together these studies demonstrate that resting EEG asymmetry and changes in EEG asymmetry during stressful task conditions are related to individual differences in infants' and children's tendencies to approach or withdraw from novel and mildly stressful events.

Temperamental differences in cortical asymmetries have also been observed while infants process different facial expressions. Specifically, de Haan, Belsky, Reid, Volein, and Johnson (2004) reported that 7-month-old infants rated high in temperamental fear, showed larger amplitude Nc responses over the right hemisphere to fearful versus happy faces. The Nc is an ERP component characterized as a negative deflection in the ongoing EEG that is most prominent at fronto-central recording sites. The Nc is thought to reflect attentional arousal and orienting (Courchesne, Ganz, \& Norcia, 1981; Nelson, 1994; Richards, 2003). Therefore, this finding was interpreted as reflecting fearful infants' tendencies to be sensitive to signs of novelty and to more easily engage the right hemisphere while processing negative emotions (e.g., Field, Pickens, Fox, Gonzalez, \& Nawrocki, 1998).

Measures of total cortical EEG power have been associated with additional variables related to temperament and social behavior. Specifically, Henderson et al. (2004) found that right frontal EEG asymmetry discriminated amongst preschoolers who engaged in high versus low levels of social play when interacting in a small group of unfamiliar peers. However, total cortical power discriminated between children who displayed qualitatively different types of non-social play. Specifically, children who engaged in solitary-constructive play (e.g., playing with puzzles or coloring pictures) showed right-frontal EEG activity and relatively high levels of cortical power across all scalp regions (frontal, central, parietal, and occipital). In contrast, preschoolers who engaged in reticent behaviors, for example hovering and onlooking, showed right frontal EEG activity and relatively low levels of cortical power across all scalp regions. Given the inverse association between power and activation in the alpha band, this finding suggests that socially reticent children have elevated levels of cortical activity. This pattern of elevated activity may be indicative of a hyper-vigilant state in which these fearful children are closely monitoring the unfamiliar environment for any signs of threat (Kapp, Supple, \& Whalen, 1994). Interestingly, compared to typically developing controls, higher functioning children with autism show decreased cortical activation (or higher cortical power) across anterior, central, and posterior scalp regions which may reflect a general lack of orientation to the surrounding environment, a pattern that is consistent with the social and emotional profile in these children (Sutton et al., 2005).

Although there is a good deal of consistency in the findings relating patterns of anterior EEG asymmetry to BIS/BAS tendencies in children and adults, there is still some uncertainty regarding the neural bases for these observed differences. Specifically, it is not clear whether differences in frontal EEG asymmetry reflect differences in activation at the frontal sites from which the EEG is recorded, or differences in activation of other cortical 
and/or subcortical regions that project to and are recorded within each hemisphere (Davidson, 1998a). Davidson (1998a) emphasized that measures that allow for greater spatial resolution such as fMRI need to be collected in conjunction with scalp-recorded EEG to further explore the neural origins of the resting asymmetries. While the asymmetries may reflect hemispheric differences in patterns of cortical arousal, they could also reflect differences in patterns of activation of several subcortical structures with direct projections to the frontal cortex including the amygdala, thalamus, periaqueductal gray, and locus coeruleus (Baumgarten, 1993; Davidson, 1998a, 1998b; Wieser \& Siegel, 1993).

\section{The CNS and self-regulation}

Self-regulation is a core aspect of many models of temperament. In Rothbart's model of temperament, self-regulation includes the attentional and effortful processes that function to modulate an individual's reactive tendencies (Rothbart \& Derryberry, 1981; Ruff \& Rothbart, 1996). Early in infancy the use of attention in the service of emotional regulation is involuntary, being driven primarily by the nature of external stimulation (Derryberry $\&$ Rothbart, 1997). From the first days following birth, caregivers rely heavily on reorienting and engaging their infants' attention, using techniques such as providing distracting objects as a soothing strategy to help young infants manage their emotions (e.g., Harman, Rothbart, \& Posner, 1997). As the child develops, attention is deployed in more flexible, intentional, and self-directed ways, providing the basis for self-regulation (Kopp, 1982). Individual differences in the tendency to easily focus and shift attention are captured on several different parent report measures of temperament (Rothbart \& Bates, 1998). For example, Thomas and Chess included dimensions of distractibility and attention span/persistence in their original nine dimensions of temperament. The Infant Behavior Questionnaire (IBQ) includes a dimension called duration of orienting, the TBAQ includes an interest dimension which describes children's tendencies to remain focused on specific activities, and the CBQ (Children's Behavioral Questionnaire) includes an attention focusing dimension. Attention or orienting dimensions are also coded on laboratory based assessments of temperament (Goldsmith \& Rothbart, 1996; Matheny, 1991). Whether assessed through parent report measures or observationally, individual differences in these attentional processes also show significant stability over time (e.g., Kochanska, Murray, \& Harlan, 2000; Murphy, Eisenberg, Fabes, Shepard, \& Guthrie, 1999).

There tends to be a positive association between children's capacities to focus and shift attention and their ability to regulate their behavioral and emotional reaction tendencies (Ruff \& Rothbart, 1996). For example, newborns who engage in relatively long periods of visual orienting show fewer state fluctuations and are slower to reach peak intensities of negative affect compared to newborns who engage in less visual orienting (Strauss \& Rourke, 1978). By 4 months of age, infants who are better able to disengage their attention from a central stimulus upon presentation of a peripheral stimulus are rated by their mothers as experiencing less distress and as being more soothable (Johnson, Posner, \& Rothbart, 1991). As attention becomes more internally-controlled with increasing age, these attention abilities appear to cluster together with other emerging executive abilities. Based on factor analytic studies using the Child Behavior Questionnaire (CBQ) for 3- to 7- yearold children, Ahadi et al. (1993) identified a broad factor labeled effortful control that incorporates temperament dimensions related to attentional control with other dimensions reflecting children's capacities for intentionally inhibiting their behaviors. Specific 
dimensions included in the Effortful Control factor are: attentional focusing, inhibitory control, perceptual sensitivity, and low intensity pleasure.

In general, effortful control describes a constellation of cognitive and attentional strategies that function to regulate behaviors and emotions through voluntary inhibition, response modulation, and self-monitoring. Specific skills underlying effortful control include those broadly conceived of as executive functions including response inhibition, resistance to interference, response sequencing, and error detection, which together allow for the planning, initiation, and regulation of goal-directed behavior (Bjorklund \& Kipp, 1996; Posner \& Rothbart, 2000; Rothbart \& Bates, 1998; Stuss \& Benson, 1984). Executive functioning plays such a central role in self-regulation that deficits in executive functions are identified as a central component in a variety of developmental psychopathologies including attention deficit hyperactivity disorder, conduct disorder, and substance abuse (Gorenstein, 1987; Moffitt, 1993; Nigg, 2000). Executive function deficits are also associated with behavioral adjustment difficulties including impulsive aggression (Giancola \& Zeichner, 1994) and a propensity for fighting (Seguin, Pihl, Harden, Tremblay, \& Boulerice, 1995). In contrast, high levels of effortful control and executive functioning tend to be associated with positive developmental outcomes including the development of empathy and conscience (Eisenberg, 2000; Kochanska, 1997; Kochanska et al., 2000). Together these findings suggest that the specific abilities subsumed under the broad concept of effortful control form the basis for well-regulated behavior and emotion, whereas deficits in these skills serve as a general risk for poorly regulated approach or appetitive responses.

Similar to the literature relating temperament measures of sustained attention to emotion regulation in infancy, both parent reports and observational measures of attentional and effortful control in childhood tend to be inversely associated with measures of negative affect and emotional and behavioral dysregulation. In order to assess aspects of executive control in 2- to 3-year-old preschool children, Gerardi-Caulton and colleagues developed a version of the Stroop task appropriate for young children (Gerardi-Caulton, 2000). In this task, spatial conflict was elicited by asking children to pay attention to visual stimuli presented either on the left or right side of a computer monitor. The child was asked to press a button that corresponded to the content of the stimulus rather than the position of the stimulus. In order to perform well on the task, children had to inhibit the prepotent tendency to respond based on the spatial location of the target. Cross-sectionally, there were strong age-related effects on performance between 2 and 3 years of age, with the most dramatic change occurring at about 30 months of age. Importantly, children's performance on this task correlated with maternal reports of temperament on the CBQ. Specifically, children whose performance was less affected by the visual-spatial conflict were rated higher on maternal reports of effortful control and lower on maternal reports of negative affect (Gerardi-Caulton, 2000; Rothbart, Ellis, Rueda, \& Posner, 2003).

The regulatory function of effortful control can also be documented in studies examining the combined influence of reactivity and self-regulation on developmental dysfunction. Elementary school-age children who are high in negative emotionality are at significantly lower risk for both concurrent and later behavioral adjustment problems if they also have high levels of attentional regulation (Eisenberg et al., 1996, 2000, 2004). Similarly, Henderson, Schwartz, Mejia and Moas (2005) found that high levels of self-reported attentional control were predictive of a less negative attribution style and lower levels of social anxiety among young adolescents who were also high in shyness; however, attentional control was not a significant predictor for children who were not shy. Such associations can be interpreted as 
reflecting the higher-order or superordinate control of attentional and effortful processes over more reactive aspects of temperament such as negative emotionality and shyness (e.g., Rothbart et al., 1994; Rothbart \& Bates, 1998; Rothbart \& Posner, 1985). That is, effortful control is thought to function as an executive system that monitors, modulates, and regulates more reactive aspects of temperament. This interpretation is consistent with dualistic or top-down models of self-regulation that propose that higher-order cognitive and executive functions down-regulate or modulate lower-order emotional reactions (Banfield, Wyland, Macrae, Munte, \& Heatherton, 2004; Luria, 1966; Norman \& Shallice, 1986).

The research summarized in this section illustrates how progress across disciplines (e.g., neuroscientific and behavioral studies) can be linked to advance our understanding. Advances in cognitive neuroscience have allowed researchers to describe (1) the neural networks associated with executive functioning and effortful control and (2) the interactions between these networks and subcortical systems governing the emotional and motivational processes considered parts of temperamental reactivity (see Posner \& Rothbart, 2000). These advances allow for a greater understanding of the interacting nature of reactive and self-regulatory processes in terms of their temporal associations and their combined influence on social and emotional outcomes.

\section{The anterior attention system and effortful control}

Posner and Rothbart attribute developmental changes and individual differences in effortful control to a set of inter-related brain regions referred to as the anterior attention system. The anterior attention system includes the ventromedial-orbitofrontal cortex, the dorsolateral prefrontal cortex, the anterior cingulate cortex, and the basal ganglia, which together facilitate the voluntary control of thoughts and emotions (Posner \& Raichle, 1994). Consistent with the idea that temperament is at least in part heritable, Posner and colleagues have recently documented patterns of heritability for executive attention abilities (Fan, Wu, Fossella, \& Posner, 2001), as well as associations between polymorphisms of the dopamine gene DAT1 and executive attention (Rueda et al., 2005). Specifically, Rueda et al. reported that children with the pure long allele were less affected by cognitive conflict in a modified flanker task compared to children who had the long/short heterozygous form. Based on results of neuroimaging findings during performance of executive attention tasks, Fan, Fossella, Sommer, and Posner (2003) have hypothesized that the associations between dopamine receptors and executive functioning are mediated through increased activity in the anterior cingulate. In contrast to the neural structures underlying individual differences in motivational tendencies, such as the amygdala and hypothalamus, which are relatively well developed at birth, the prefrontal cortex and associated regions underlying executive control have a more prolonged developmental time course. Developmental changes in effortful control capabilities have been documented based on behavioral performance on cognitive tasks requiring executive control such as Stroop, flanker, and go/no-go tasks. Effortful behaviors attributed to the anterior attention system, such as the ability to inhibit prepotent responses, resist interference and detect and correct errors, increase steadily on such tasks from the toddler years through early adolescence (e.g., Carver, Livesey, \& Charles, 2001; Casey et al., 1997; Diamond, 1990; Diamond \& Taylor, 1996; Enns, Brodeur, \& Trick, 1998; Gerstadt, Hong, \& Diamond, 1994; Hooper, Luciana, Conklin, \& Yarger, 2004; Jones, Rothbart, \& Posner, 2003; Kochanska et al., 2000; Passler, Isaac, \& Hynd, 1985; Rothbart et al., 2003). These behavioral findings are generally paralleled by neuroimaging findings showing that children 
activate the same cortical regions as adults while performing such tasks, however, the degree of activation tends to be inversely related to age. Specifically, during response inhibition tasks such as the go/no-go task, both adults and children activate ventral and dorsal regions of the prefrontal cortex, however, children show a greater extent of activation during performance than do adults (e.g., Bunge, Dudukovic, Thomason, Vaidya, \& Gabrieli, 2002; Casey et al., 1997; Durston et al., 2002). These findings are interpreted as reflecting the fact that the prefrontal cortex undergoes many age-related structural and functional changes that impact upon the efficiency of functioning including changes in synaptic density (Huttenlocher, 1979, 1990), metabolic and electrical activity (Luciana \& Nelson, 1998; Rubia et al., 2000), and changes in myelination (Pfefferbaum et al., 1994).

Like other structures in the anterior attention system, the anterior cingulate cortex (ACC) has a protracted period of development which corresponds to gradual increases in executive control throughout childhood and adolescence. Tasks involving cognitive conflict, such as the standard Stroop task, activate dorsal and posterior regions of the ACC, regions that have extensive connections with lateral prefrontal cortex, parietal cortex, premotor areas, and supplementary motor areas (Bush et al., 1998; Devinsky, Morrell, \& Vogt, 1995). The functions of the ACC include attention modulation, competition monitoring, and error detection. In parallel to the behavioral studies cited above, both fMRI and ERP studies support the central role of the ACC in response monitoring and error detection. In addition, recent developmental studies suggest that the gradual development of the ACC throughout childhood and adolescence may underlie developmental changes in performance. For example, Casey et al. (1997) reported that the volume of the right ACC, controlling for age, was positively correlated with 5- to 16-year-old children's performance on a go/no-go task. In a separate fMRI study of 7- to 12-year-old children performing a go/no-go task, trials that tapped inhibitory control activated dorsolateral and orbitofrontal PFC, but only orbitofrontal and anterior cingulate activity correlated with behavioral performance (Casey et al., 1997). Similarly, Lamm, Zelazo, and Lewis (2006) reported age-related decreases in the amplitude of the N2, an ERP component associated with response inhibition and conflict monitoring, recorded while 7- to 16year-old children performed a go/no-go task. This developmental change in amplitude is interpreted as reflecting the increased efficiency of prefrontal functioning underlying response inhibition. Davies, Segalowitz, and Gavin (2004) also found age-related increases in the amplitude of the error-related negativity in a sample of 7- to 25 -year olds. The ERN is an ERP component associated with error-monitoring and localized to the ACC and the increased amplitude seen with age may reflect changes in ACC functioning that facilitate improvements in error-monitoring throughout adolescence.

The gradual development of the neural circuitry underlying effortful control, and therefore the executive cognitive functions associated with emerging self-regulatory skills, opens up a particularly exciting area of future research in the study of temperament. Normative developmental changes in effortful processing and underlying neural systems, allows for the study of the effects of genes, experience, and individual differences on the emergence of self-regulatory processes at both biological and behavioral levels of analysis. For example, recent findings showing that individual differences in trajectories of change in the volume of the prefrontal cortex across childhood and adolescence are associated with individual differences in IQ (e.g., Shaw et al., 2006) raise interesting questions about possible associations between trajectories of neural growth and individual differences in selfregulation. 


\section{Modeling cognition-emotion interactions through cortical-subcortical interactions}

While reactive and self-regulatory processes in temperament are often presented as orthogonal constructs, they are clearly interdependent at neural, functional, and behavioral levels of analysis. Rothbart and Posner and their colleagues propose that it is the moment-to-moment interactions between the limbic system and higher cortical functions that form the basis of self-regulation (Bush, Luu, \& Posner, 2000; Rothbart \& Bates, 1998). Similarly, Davidson (1998a, 1998b) emphasized that emotional reactions and their regulation are tightly coupled, since emotions are rarely generated in the absence of the recruitment of associated regulatory processes. Consistent with the regulatory function of Posner's anterior attention system, Davidson (2000) and others have proposed that the PFC plays a central role in affective responding by modulating or regulating the time course of emotional reactions. For example, extensive reciprocal connections between the amygdala and the prefrontal cortex, particularly the medial and orbital regions of PFC, suggest that the PFC provides important inhibitory inputs into the amygdala (Amaral, Price, Pitkanen, \& Carmichael, 1992; Davidson, 1998a, 1998b, 2002; Hariri et al., 2000). Further, associations between serotonin transporter gene status and stress reactivity that were initially hypothesized to reflect individual differences in amygdala reactivity have recently been reinterpreted as reflecting associations to the coupling of prefrontal functions related to attention regulation and the reactivity of the amygdala (e.g., Heinz et al., 2005).

Because the ACC has intricate patterns of afferent and efferent connections, it is considered a relay station between the emotional processes governed by the limbic system and the higher-cognitive processes governed in large part by the prefrontal cortex. As such, it seems particularly important when considering the interplay of cognition and emotion. Specifically, tasks requiring the processing of emotional stimuli such as Stroop tasks employing negatively-valenced words as stimuli, activate anterior portions of the ACC. These regions have extensive connections with limbic and paralimbic regions including the amygdala, the orbitofrontal cortex, the periaqueductal gray, nucleus accumbens, and hypothalamus, and they outflow to autonomic, visceromotor, and endocrine systems (Devinsky et al., 1995; Whalen et al., 1998). The affective subdivision of the ACC is involved in assessing the salience of emotional and motivational information and regulation of emotional responses (Bush et al., 2000; Mayberg, 1997). This subdivision of the ACC is thought to function as a neural alarm system that is engaged when a response is inappropriate or in conflict with current goals or intentions (Bush et al., 2000). This continuous self-monitoring is considered an essential process for self-regulation (e.g., Carver \& Scheier, 1998) and has been proposed as the cognitive basis for the emergence of selfregulation in young children (e.g., Kopp, 1982).

A recent fMRI study demonstrates the ongoing interplay between the ACC and the prefrontal cortex during an emotionally arousing task related to social exclusion. Eisenberger, Lieberman, and Williams (2003) reported that young adults who were made to believe they were being excluded from an online interactive game showed increased dorsal ACC activation relative to a condition in which they were included in the game. Further, the extent of ACC activation was positively correlated with a participants' self-reports of distress. In addition to dorsal ACC activation, there were increases in right ventral PFC activation during exclusion and the extent of activation was negatively related to both ACC activity and self-reported distress. Importantly, the association between right ventral PFC activity 
and self-reported distress was mediated by ACC activation, suggesting that right ventral PFC regulates distress via efferent connections and regulation of the ACC.

Although such studies relate nicely to the theoretical models of temperament and selfregulation, there are very few fMRI studies of typically developing children examining the associations between reactive and regulatory processes at the neural level. While fMRI is noninvasive and offers excellent spatial resolution, participants must sit very still for extended periods of time and remain in a confined space, making the procedure difficult for many young children. In addition, the temporal resolution of fMRI is relatively poor, which means that many temperament-related questions regarding the temporal course of reactive and self-regulatory tendencies cannot be well addressed in fMRI studies. Instead, the majority of studies relating temperament to these processes involve the use of behavioral marker tasks, such as the modified Stroop task for children described above, that are designed to tap into the functions of these neural systems in the absence of direct measurement of cortical functioning. As tasks assessing the functioning of the anterior attention system at a behavioral level become more standard parts of temperament assessment batteries, the ability to examine the interactions between these behaviors and reactive temperamental tendencies will be improved.

\section{Contextual influences on CNS functioning related to temperament}

Defining temperament as relatively stable and biologically based seems to imply that temperament is predetermined by our genetic inheritance and therefore impervious to contextual influences. Traditionally, the term context as used by developmental researchers refers to the individuals "psychosocial context" (e.g., parent child rearing strategies, daycare or school conditions, peer group characteristics, cultural value systems). However, children also live in a bio-ecological context, defined by ecological characteristics such as environmental pollution, availability and variety of nutrients and exposure to infectious agents. Understanding the role of context upon both brain and behavioral development requires the simultaneous consideration of both psychosocial and bio-ecological characteristics (Wachs, 2003). In support of this conclusion, evidence from a number of studies demonstrates the powerful effects of bio-ecological (e.g., nutrition) and psychosocial (e.g., caregiving experiences) factors on the expression of temperament related behaviors. Further, a number of these effects appear to be mediated through the influence of contextual characteristics on common temperament-related aspects of CNS functioning.

An important bio-ecological factor is iron deficiency. Distinct temperament profiles including heightened levels of negative affect, increased inhibition and lower levels of attention have been linked to impaired iron status assessed during the prenatal period (Vaughn, Brown, \& Carter, 1986), at birth (Tamura et al., 2002; Wachs, Pollitt, Cueto, Jacoby, \& Creed-Kanashiro, 2005) and infancy (Lozoff et al., 2003, 1998). Results from a recently completed study have also shown that lower levels of maternal hemoglobin during pregnancy and lower levels of neonatal iron stores (ferritin) are both linked to reduced intra-individual variability (lower reactivity) in infant temperament at 3 months of age (Wachs et al., 2006). In addition, there is evidence that the behavioral consequences of pre, neo and postnatal iron deficiency may be mediated by changes in CNS development and function. Infrahuman studies have consistently documented the adverse consequences of iron deficiency during infancy on hippocampal development, myelination and density of dopamine receptors and serotonin and norepinephrine transporter densities (Beard \& 
Connor, 2003; Lozoff et al., 2006). Changes in dopamine receptors as a function of iron deficiency may be particularly salient for the development of temperament, given the known role of dopamine in the modulation of attention, behavioral activation and inhibition (Lozoff et al., 2006). While far less is known about the neural consequences of early iron deficiency at the human level, research involving human neonates (Siddappa et al., 2004) and preschool age children (Algarin, Peirano, Garrido, Pizarro, \& Lozoff, 2003) indicates alterations in functional brain electrical activity as a function of iron deficiency.

With regard to psychosocial influences, there is a substantial research literature on the influence of parenting rearing styles on offspring temperament (Wachs, 2006), as well as a growing literature on interactions between parenting and child temperament as predictors of subsequent development and adjustment (Kochanska, 1997; Lengua, Wolchik, Sandler, \& West, 2000; Morris et al., 2002; Wills, Sandy, Yaeger, \& Shiner, 2001). In addition, psychosocial contextual effects on temperament and associated CNS functions are also beginning to be examined in infrahuman and human populations. Meaney and colleagues have studied the effects of variations in rats' maternal caregiving behaviors on the neural substrates underlying behavioral and endocrine responses to stress in offspring (Caldji et al., 1998; Francis, Diorio, Liu, \& Meaney, 1999). Specifically, the adult offspring of mothers displaying low levels of licking, grooming, and arch-backed nursing show heightened stress sensitivity expressed in both behavioral and neuroendocrine responses (Caldji et al., 1998; Francis et al., 1999). Using a cross-fostering design, these behavioral and neuroendocrine responses were attributable to these caregiving experiences and not genetic inheritance from the biological parents. Such findings raise interesting questions about parallel processes relating contextual factors, such as caregiving history, to the expression of temperament in humans.

In order to begin to address parallel questions in human infants, Hane and Fox (2006) reported that 9-month-old infants receiving relatively insensitive and intrusive maternal caregiving displayed higher levels of fearfulness, initiated fewer joint attention bids, and displayed greater right frontal asymmetry in the first year of life. These differences were not accounted for by earlier measures of infant temperament, suggesting that caregiving experiences may influence the behavioral and neural systems underlying negative affect and stress responding.

\section{Conclusions and future directions}

We believe that current theory and research on developmental and individual differences in temperament provides a model field of study within which developmental psychologists are addressing questions related to the nature of cognition-emotion interactions and their impact on development across childhood. As this review demonstrates, temperament researchers have made great progress relating tonic or baseline measures of CNS functioning to individual differences in reactive and self-regulatory behaviors. However, we are just beginning to design study protocols that include assessments of neural functioning during tasks that elicit developmental and individual differences in levels of reactivity or self-regulation. This is clearly not an easy task, given the complexity of implementing research protocols with the level of detail and psychometric rigor used in traditional behavioral assessments of temperament and social behavior within an EEG/ERP or fMRI testing environment. However, there are several examples of creative assessment approaches that do accomplish this goal (e.g., Eisenberger, 2006; Rueda et al., 2005). 
In addition, given our knowledge of the coupling of reactive and self-regulatory neural processes and the parallel theoretical emphasis on the combined effects of reactivity and self-regulation on adjustment, it seems particularly important that we design both behavioral and physiological assessments of this dynamic interaction. Rather than working to design independent assessments of reactivity versus self-regulation, tasks can be designed that simultaneously trigger both processes, allowing for analyses of their temporal progression and dynamic interaction.

Finally, we believe it is essential to study the development of temperament and the neural processes underlying reactivity and self-regulation across infancy, childhood, and adolescence. Given only modest levels of stability in assessments of temperament across time, the protracted developmental course of many neural structures underlying self-regulation and the effects of bio-ecological and psychosocial contextual factors on temperamentrelated CNS functioning, studying these processes at any given point in development will only provide a snapshot of cognition-emotion interactions underlying social development. By incorporating longitudinal assessments of both behavior and neural functioning, we will begin to be able to address truly developmental questions, such as the effects of emotional reactivity in infancy on the development of the anterior attention network in early childhood and the neural mechanisms underlying contextual influences on the expression of temperament.

\section{References}

Ahadi, S., Rothbart, M., \& Ye, R. (1993). Child temperament in the US and China: Similarities and Differences. European Journal of Personality, 7, 359-378.

Algarin, C., Peirano, P., Garrido, M., Pizarro, F., \& Lozoff, B. (2003). Iron deficiency anemia in infancy: Longlasting effects on auditory and visual system functioning. Pediatric Research, 53, 217-223.

Amaral, D. G., Price, J. L., Pitkanen, A., \& Carmichael, S. T. (1992). Anatomical organization of the primate amygdaloid complex. In J. P. Aggleton (Ed.), The amygdala: Neurobiological aspects of emotion, memory, and mental dysfunction (pp. 1-66). New York: Wiley-Liss.

Auerbach, J., Geller, V., Lezer, S., Shinwell, E., Belmaker, R. H., Levine, J., et al. (1999). Dopamine D4 receptor (DRD4) and serotonin transporter promoter (5-HTTLPR) polymorphisms in the determination of temperament in 2-month-old infants. Molecular Psychiatry, 4, 369-373.

Baird, A. A., Gruber, S. A., Fein, D. A., Maas, L. C., Steingard, R. J., Renshaw, P. F., et al. (1999). Functional magnetic resonance imaging of facial affect recognition in children and adolescents. Journal of the American Academy of Child and Adolescent Psychiatry, 38, 195-199.

Banfield, J. F., Wyland, C. L., Macrae, C. N., Munte, T. F., \& Heatherton, T. F. (2004). The cognitive neuroscience of self-regulation. In R. F. Baumeister \& K. D. Vohs (Eds.), Handbook of self-regulation: Research, theory, and applications (pp. 62-83). New York, NY: Guilford.

Bates, J. E. (1989). Concepts and measures of temperament. In G. A. Kohnstamm, J. E. Bates, \& M. K. Rothbart (Eds.), Temperament in childhood (pp. 3-26). Oxford, England: Wiley.

Bates, J. E. (2001). Adjustment style in childhood as a product of parenting and temperament. In T. D. Wachs \& G. A. Kohnstamm (Eds.), Temperament in context (pp. 173-200). Mahwah, NJ: Lawrence Erlbaum.

Baumgarten, H. G. (1993). Control of vigilance and behavior by ascending serotinergic systems. In S. Zschocke \& E.-J. Speckmann (Eds.), Basic mechanisms of the EEG (pp. 231-268). Boston, MA: Birkhauser.

Beard, J., \& Connor, J. (2003). Iron status and neural functioning. Annual Review of Nutrition, $23,41-58$.

Belsky, J., Friedman, S. L., \& Hsieh, K. H. (2001). Testing a core emotion-regulation prediction: Does early attentional persistence moderate the effect of infant negative emotionality on later development? Child Development, 72, 123-133.

Berridge, K. C. (1996). Food reward: Brain substrates of wanting and liking. Neuroscience and Biobehavioral Reviews, 20, 1-25.

Bjorklund, D. F., \& Kipp, K. (1996). Parental investment theory and gender differences in the evolution of inhibition mechanisms. Psychological Bulletin, 120, 163-188. 
Bornstein, M. H., Gaughran, J. M., \& Segui, I. (1991). Multimethod assessment of infan temperament: Mother questionnaire and mother and observer reports evaluated and compared at five months using the Infant Temperament Measure. International Journal of Behavioral Development, 14, 131-151.

Bunge, S. A., Dudukovic, N. M., Thomason, M. E., Vaidya, C. J., \& Gabrieli, J. D. (2002). Immature frontal lobe contributions to cognitive control in children. Evidence from fMRI. Neuron, 33, 301-311.

Bush, G., Luu, P., \& Posner, M. I. (2000). Cognitive and emotional influences in anterior cingulate cortex. Trends in Cognitive Sciences, 4, 215-222.

Bush, G., Whalen, P. J., Rose, B. R., Jenike, M. A., McInerney, S. C., \& Rauch, S. L. (1998). The counting Stroop: An interference task specialized for functional neuroimaging - validation study with functional MRI. Human Brain Mapping, 6, 270-280.

Caldji, C., Tannenbaum, B., Sharma, S., Francis, D., Plotsky, P. M., \& Meaney, M. J. (1998). Maternal care during infancy regulates the development of neural systems mediating the expression of fearfulness in the rat. Proceedings of the National Academy of Sciences, USA, 95, 5335-5340.

Calkins, S. D., Fox, N. A., \& Marshall, T. R. (1996). Behavioral and physiological antecedents of inhibited and uninhibited behavior. Child Development, 67, 523-540.

Canli, T., Sivers, H., Whitfield, S. L., Gotlib, I. H., \& Gabrieli, J. D. E. (2002). Amygdala response to happy faces as a function of extraversion. Science, 96, 2191.

Carver, A. C., Livesey, D. J., \& Charles, M. (2001). Age related changes in inhibitory control as measured by stop signal task performance. International Journal of Neuroscience, 107, 43-61.

Carver, C. (2004). Negative affects deriving from the Behavioral Approach System. Emotion, 4, 3-22.

Carver, C. S., \& Scheier, M. F. (1998). On the self-regulation of behavior. New York: Cambridge University Press.

Carver, C. S., \& White, T. L. (1994). Behavioral inhibition, behavioral activation, and affective responses to impending reward and punishment: The BIS/BAS Scales. Journal of Personality and Social Psychology, 67, $319-333$.

Casey, B. J., Trainor, R. J., Orendi, J. L., Schubert, A. B., Nystrom, L. E., Giedd, J. N., et al. (1997). A developmental functional MRI study of prefrontal activation during performance of a Go-No-Go task. Journal of Cognitive Neuroscience, 9, 835-847.

Caspi, A. (1998). Personality development across the life course (5th ed.. In W. Damon \& N. Eisenberg (Eds.). Handbook of child psychology: Social, emotional, and personality development (Vol. 3, pp. 311-388). Hoboken, NJ: Wiley.

Caspi, A., McClay, J., Moffitt, T., Mill, J., Martin, J., Craig, I. W., et al. (2002). Role of genotype in the cycle of violence in maltreated children. Science, 297, 851-854.

Cloninger, C. R. (1987). A systematic method for clinical description and classification of personality variants: A proposal. Archives of General Psychiatry, 44, 573-588.

Coan, J. A., \& Allen, J. J. B. (2003). Frontal EEG asymmetry and the behavioral activation and inhibition systems. Psychophysiology, 40, 106-114.

Courchesne, E., Ganz, L., \& Norcia, A. M. (1981). Event-related brain potentials to human faces in infants. Child Development, 52, 804-811.

Davidson, R. J. (1993). Cerebral asymmetry and emotion: Conceptual and methodological conundrums. Cognition and Emotion, 7, 115-138.

Davidson, R. J. (1998a). Affective style and affective disorders: Perspectives from affective neuroscience. Cognition and Emotion, 12, 307-330.

Davidson, R. J. (1998b). Anterior electrophysiological asymmetries, emotion, and depression: Conceptual and methodological conundrums. Psychophysiology, 35, 607-614.

Davidson, R. J. (2000). Affective style, psychopathology and resilience: Brain mechanisms and plasticity. American Psychologist, 55, 1196-1214.

Davidson, R. J. (2002). Anxiety and affective style: Role of prefrontal cortex and amygdala. Biological Psychiatry, $51,68-80$.

Davidson, R. J., Chapman, J. P., Chapman, L. J., \& Henriques, J. B. (1990). Asymmetrical brain electrical activity discriminates between psychometrically-matched verbal and spatial cognitive tasks. Psychophysiology, 27, 528-543.

Davidson, R. J., \& Fox, N. A. (1989). Frontal brain asymmetry predicts infants' response to maternal separation. Journal of Abnormal Psychology, 98, 127-131.

Davidson, R. J., Jackson, D. C., \& Larson, C. L . (2000). Human electroencephalography. In J. T. Cacioppo, L. G. Tassinary, \& G. G. Berntson (Eds.), Handbook of psychophysiology (2nd ed., pp. 27-52). New York, NY, US: Cambridge University Press. 
Davies, P. L., Segalowitz, S. J., \& Gavin, W. J. (2004). Development of response-monitoring ERPs in 7- to 25year-olds. Developmental Neuropsychology, 25, 355-376.

Davis, M. (1992). The role of the amygdala in fear and anxiety. Annual Review of Neuroscience, 15, 353-375.

de Haan, M., Belsky, J., Reid, V., Volein, A., \& Johnson, M. H. (2004). Maternal personality and infants' neural and visual responsivity to facial expressions of emotion. Journal of Child Psychology and Psychiatry, 45, $1209-1218$.

Depue, R. A., \& Collins, P. F. (1999). Neurobiology of the structure of personality: Dopamine, facilitation of incentive motivation, and extraversion. Behavioral and Brain Sciences, 22, 491-569.

Depue, R. A., \& Iacono, W. G. (1989). Neurobehavioral aspects of affective disorders. In: M. R. Rosenzweig, \& L. W. Porter (Eds.), Annual review of psychology (Vol. 40, pp. 457-492). Palo Alto, CA, US: Annual Reviews.

Derryberry, D., \& Rothbart, M. (1997). Reactive and effortful processes in the organization of temperament. Development and Psychopathology, 9, 633-652.

Devinsky, O., Morrell, M. J., \& Vogt, B. A. (1995). Contributions of anterior cingulate cortex to behaviour. Brain. A Journal of Neurology, 118, 279-306.

Diamond, A. (1990). Developmental time course in human infants and infant monkeys, and the neural bases of inhibitory control in reaching. Annals of the New York Academy of Sciences, 608, 637-676.

Diamond, A., \& Taylor, C. (1996). Development of an aspect of executive control: Development of the abilities to remember what I said and to 'do as I say, not as I do'. Developmental Psychobiology, 29, 315-334.

Diamond, S. (Ed.). (1974). The roots of psychology: A sourcebook in the history of ideas. Oxford, England: Basic Books.

DiPietro, J. A., Bornstein, M. H., Costigan, K. A., Pressman, E. K., Hahn, C. S., \& Painter, K. (2002). What does fetal movement predict about behavior during the first two years of life? Developmental Psychobiology, 40, $358-371$.

DiPietro, J. A., Hodgson, D. M., Costigan, K. A., \& Johnson, T. R. B. (1996). Fetal antecedents of infant temperament. Child Development, 67, 2568-2583.

Durston, S., Thomas, K. M., Yang, Y., Ulug, A. M., Zimmerman, R. D., \& Casey, B. J. (2002). A neural basis for the development of inhibitory control. Developmental Science, 5, F9-F16.

Eaton, W. O., \& Dureski, C. M. (1986). Parent and actometer measures of motor activity level in the young infant. Infant Behavior and Development, 9, 383-393.

Eisenberg, N. (2000). Emotion, regulation, and moral development. Annual Review of Psychology, 51, 665-697.

Eisenberg, N. (2002). Emotion-related regulation and its relation to quality of social functioning. In: W. Hartup $\&$ R. A. Weinberg (Eds.), The Minnesota symposia on child psychology, Vol. 32. Child psychology in retrospect and prospect: In celebration of the 75th anniversary of the Institute of Child Development. (pp. 133-171). Mahwah, NJ, US: Lawrence Erlbaum.

Eisenberg, N., Cumberland, A., Spinrad, T. L., Fabes, R. A., Shepard, S. A., Reiser, M., et al. (2001). The relations of regulation and emotionality to children's externalizing and internalizing problem behavior. Child Development, 72, 1112-1134.

Eisenberg, N., Fabes, R. A., Guthrie, I. K., Murphy, B. C., Losoya, S. H., \& Guthrie, I. K. (1996). The relations of regulation and emotionality to problem behavior in elementary school children. Development and Psychopathology, 8, 141-162.

Eisenberg, N., Guthrie, I., Fabes, R., Shepard, S., Losoya, S., Murphy, B., et al. (2000). Prediction of elementary school children's externalizing behavior problems from attentional and behavioral regulation and negative emotionality. Child Development, 71, 1367-1382.

Eisenberg, N., Spinrad, T. L., Fabes, R. A., Reiser, M., Cumberland, A., Shepard, S. A., et al. (2004). The relations of effortful control and impulsivity to children's resiliency and adjustment. Child Development, 75, $25-46$.

Eisenberger, N. I., Lieberman, M. D., \& Williams, K. D. (2003). Does rejection hurt? An fMRI study of social exclusion. Science, 302, 290-292.

Eisenberger, N. I. (2006). Identifying the neural correlates underlying social pain: Implications for developmental process. Human Development, 49, 273-293.

Enns, J. T., Brodeur, D. A., \& Trick, L. M. (1998). Selective attention over the life span: Behavioral measures. In J. E. Richards (Ed.), Cognitive neuroscience of attention: A developmental perspective (pp. 393-418). Mahwah, NJ: Lawrence Erlbaum.

Eysenck, H. J. (1967). The biological basis of personality. Springfield, IL: Thomas.

Fan, J., Fossella, J. A., Sommer, T., \& Posner, M. I. (2003). Mapping the genetic variation of executive attention onto brain activity. Proceedings of the National Academy of Sciences, 100, 7406-7411. 
Fan, J., Wu, Y., Fossella, J., \& Posner, M. I. (2001). Assessing the heritability of attentional networks. BioMed Central Neuroscience, $2,14$.

Field, T., Pickens, J., Fox, N. A., Gonzalez, J., \& Nawrocki, T. (1998). Facial expression and EEG responses to happy and sad faces/voices by 3-month-old infants of depressed mothers. British Journal of Developmental Psychology, 16, 485-494.

Fox, N. A. (1994). If it's not left, it's right. Electroencephalograph asymmetry and the development of emotion. American Psychologist, 46, 863-872.

Fox, N. A., Henderson, H. A., Rubin, K. H., Calkins, S. D., \& Schmidt, L. A. (2001). Continuity and discontinuity of behavioral inhibition and exuberance: Psychophysiological and behavioral influences across the first four years of life. Child Development, 72, 1-21.

Fox, N. A., Nichols, K. E., Henderson, H. A., Rubin, K., Schmidt, L., Hamer, D., et al. (2005). Evidence for a gene-environment interaction in predicting behavioral inhibition in middle childhood. Psychological Science, 16, 921-926.

Francis, D., Diorio, J., Liu, D., \& Meaney, M. J. (1999). Nongenomic transmission across generations of maternal behavior and stress responses in the rat. Science, 286, 1155-1158.

Gerardi-Caulton, G. (2000). Sensitivity to spatial conflict and the development of self-regulation in children 24 36 months of age. Developmental Science, 3, 397-404.

Gerstadt, C. L., Hong, Y. J., \& Diamond, A. (1994). The relationship between cognition and action: Performance of $31 / 2-7$ year olds on a Stroop-like day-night test. Cognition, 53, 129-153.

Giancola, P. R., \& Zeichner, A. (1994). Neuropsychological performance on tests of frontal-lobe functioning and aggressive behavior in men. Journal of Abnormal Psychology, 103, 832-835.

Goldsmith, H. H. (1996). Studying temperament via construction of the Toddler Behavior Assessment Questionnaire. Child Development, 67, 218-235.

Goldsmith, H. H., \& Hewitt, E. C. (2003). Validity of parental report of temperament: Distinctions and needed research. Infant Behavior and Development, 26, 108-111.

Goldsmith, H. H., \& Rothbart, M. (1996). The laboratory temperament assessment battery manual. Madison: Personality Development Laboratory, University of Wisconsin.

Gorenstein, E. E. (1987). Cognitive-perceptual deficit in an alcoholism spectrum disorder. Journal of Studies on Alcohol, 48, 310-318.

Gottlieb, G. (2003). On making behavioral genetics truly developmental. Human Development, 46, $337-355$.

Gray, J. A. (1975). Elements of a two-process theory of learning. New York: Acamedic Press.

Gray, J. A. (1991). The neuropsychology of temperament. In J. Strelau \& A. Angleitner (Eds.), Explorations in temperament: International perspectives on theory and measurement (pp. 105-128). New York: Plenum Press.

Guerin, D., Gottfried, A., Oliver, P., \& Thomas, C. (2003). Temperament: Infancy through adolescence. New York: Kluwer Academics.

Gunnar, M. R. (1994). Psychoendocrine studies of temperament and stress in early childhood: Expanding current models. In J. E. Bates \& T. D. Wachs (Eds.), Temperament: Individual differences at the interface of biology and behavior (pp. 175-198). Washington, DC: American Psychological Association.

Gunnar, M. R. (2000). Early adversity and the development of stress reactivity and regulation. In C. A. Nelson (Ed.). The Minnesota symposia on child psychology: The effects of early adversity on neurobehavioral development (Vol. 31, pp. 163-200). Mahwah, NJ: Lawrence Erlbaum.

Hagekull, B., \& Bohlin, G. (1998). Preschool temperament and environmental factors related to the five-factor model of personality in middle childhood. Merrill-Palmer Quarterly, 44, 194-215.

Hagemann, D., Ewald, N., Thayer, J. F., \& Bartussek, D. (2002). Does resting electroencephalograph asymmetry reflect a trait? An application of latent state-trait theory. Journal of Personality and Social Psychology, 82, 619-641.

Hagemann, D., Hewig, J., Seifert, J., Naumann, E., \& Bartussek, D. (2005). The latent state-trait structure of resting EEG asymmetry: Replication and extension. Psychophysiology, 42, 740-752.

Halverson, C. F., Jr. Kohnstamm, G. A., \& Martin, R. P. (Eds.). (1994). The developing structure of temperament and personality from infancy to adulthood. Hillsdale, NJ: Lawrence Erlbaum Associates.

Hane, A. A., \& Fox, N. A. (2006). Ordinary variations in maternal caregiving influence human infants' stress reactivity. Psychological Science, 17, 550-556.

Hariri, A. R., Bookheimer, S. Y., \& Mazziotta, J. C. (2000). Modulating emotional responses: Effects of a neocortical network on the limbic system. Neuroreport, 11, 43-48. 
Hariri, A. R., Drabant, B. A., Munoz, B. A., Kolachana, B. S., Mattay, V. S., Egan, M. F., et al. (2005). A susceptibility gene for affective disorders and the response of the human amygdala. Archives of General Psychiatry, 62, 146-152.

Hariri, A. R., Mattay, V. S., Tessitore, A., Kolachana, B., Fera, F., Goldman, D., et al. (2002). Serotonin transporter genetic variation and the response of the human amygdale. Science, 297, 400-403.

Harman, C., Rothbart, M. K., \& Posner, M. I. (1997). Distress and attention interactions in early infancy. Motivation and Emotion, 21, 27-43.

Harmon-Jones, E. (2003). Anger and the behavioral approach system. Personality and the Behavioral Approach System, 35, 995-1005.

Harmon-Jones, E., \& Allen, J. J. B. (1998). Anger and frontal brain activity: EEG asymmetry consistent with approach motivation despite negative affective valence. Journal of Personality and Social Psychology, 74, 1310-1316.

Hegvik, R. L., McDevitt, S. C., \& Carey, W. B. (1982). The Middle Childhood Temperament Questionnaire. Journal of Developmental and Behavioral Pediatrics, 3, 197-200.

Heinz, A., Braus, D. F., Smolka, M. N., Wrase, J., Puls, I., Hermann, D., et al. (2005). Amygdala-prefrontal coupling depends on genetic variation of the serotonin transporter. Nature Neuroscience, 8, 20-21.

Heller, W., Koven, N. S., \& Miller, G. A. (2003). Regional brain activity in anxiety and depression, cognition/ emotion interaction, and emotion regulation. In K. Hugdahl \& R. J. Davidson (Eds.), The asymmetrical brain (pp. 533-564). Cambridge, MA: MIT Press.

Henderson, H. A., \& Fox, N. A. (2007). Considerations in studying emotion in infants and children. In J. A. Coan \& J. J. B. Allen (Eds.), The handbook of emotion elicitation and assessment (pp. 827-864). New York, NY: Oxford University Press.

Henderson, H. A., Fox, N. A., \& Rubin, K. H. (2001). Temperamental contributions to social behavior: The moderating roles of frontal EEG asymmetry and gender. Journal of the American Academy of Child and Adolescent Psychiatry, 40, 68-74.

Henderson, H. A., Marshall, P. J., Fox, N. A., \& Rubin, K. H. (2004). Psychophysiological and Behavioral Evidence for Varying Forms and Functions of Nonsocial Behavior in Preschoolers. Child Development, 75 , $236-250$.

Henderson, H. A., Schwartz, C. B., Mejia, E., \& Moas, O. L. (2005). Attentional control and the regulation of approach/withdrawal tendencies in children. Poster presented at the Biennial Meeting of the Society for Research in Child Development Temperament/Personality Preconference, Atlanta, Georgia.

Hongwanishkul, D., Happaney, K. R., Lee, W. S. C., \& Zelazo, P. D. (2005). Assessment of hot and cool executive function in young children: Age-related changes and individual differences. Developmental Neuropsychology, 28, 617-644.

Hooper, C. J., Luciana, M., Conklin, H. M., \& Yarger, R. S. (2004). Adolescents' performance on the Iowa Gambling Task: Implications for the development of decision making and ventromedial prefrontal cortex. Developmental Psychology, 40, 1148-1158.

Huffman, L. C., Bryan, Y. E., del-Carmen, R., Pedersen, F. A., Doussard-Roosevelt, J. A., \& Porges, S. W. (1998). Infant temperament and cardiac vagal tone: Assessments at twelve weeks of age. Child Development, $69,624-635$.

Huttenlocher, P. R. (1979). Synaptic density in human frontal cortex - developmental changes and effects of aging. Brain Research, 163, 195-205.

Huttenlocher, P. R. (1990). Morphometric study of human cerebral cortex development. Neuropsychologia, 28, $517-527$.

Irwin, W., Davidson, R. J., Lowe, M. J., Mock, B. J., Sorenson, J. A., \& Turski, P. A. (1996). Human amygdala activation detected with echo-planar functional magnetic resonance imaging. NeuroReport, 7, 1765-1769.

Jackson, D. C., Mueller, C. J., Dolski, I., Dalton, K. M., Nitschke, J. B., Urry, H. L., et al. (2003). Now you feel it, now you don't: Frontal brain electrical asymmetry and individual differences in emotion regulation. Psychological Science, 14, 612-617.

Jacques, D. (1881). The temperaments. New York: Fowler \& Wells.

Johnson, M. H., Posner, M. I., \& Rothbart, M. K. (1991). Components of visual orienting in early infancy: Contingency learning, anticipatory looking, and disengaging. Journal of Cognitive Neuroscience, 3, 335-344.

Jones, L. B., Rothbart, M. K., \& Posner, M. I. (2003). Development of executive attention in preschool children. Developmental Science, 6, 498-504.

Jones, N. A., Field, T., Davalos, M., \& Pickens, J. (1997). EEG stability in infants/children of depressed mothers. Child Psychiatry and Human Development, 28, 59-70. 
Kagan, J. (1994). Inhibited and uninhibited temperaments. In W. B. Carey \& S. C. McDevitt (Eds.), Prevention and early intervention: Individual differences as risk factors for the mental health of children: A festschrift for Stella Chess and Alexander Thomas (pp. 35-41). Philadelphia: Brunner/Mazel.

Kagan, J. (1998). Biology and the child (5th ed.. In W. Damon \& N. Eisenberg (Eds.). Handbook of child psychology, social, emotional, and personality development (Vol. 3, pp. 177-235). Hoboken, NJ: Wiley.

Kagan, J., Reznick, J. S., Clarke, C., Snidman, N., \& Garcia-Coll, C. (1984). Behavioral inhibition to the unfamiliar. Child Development, 55, 2212-2225.

Kagan, J., Reznick, J. S., \& Snidman, N. (1987). The physiology and psychology of behavioral inhibition in children. Child Development, 58, 1459-1473.

Kagan, J., \& Snidman, N. (2004). The long shadow of temperament. Cambridge, MA: Belknap Press of Harvard University Press.

Kapp, B. S., Supple, W. F., \& Whalen, P. J. (1994). Stimulation of the amygdaloid central nucleus produces EEG arousal. Behavioral Neuroscience, 108, 81-93.

Kerr, M., Lambert, W. W., Stattin, H., \& Klackenberg-Larsson, I. (1994). Stability of inhibition in a Swedish longitudinal sample. Child Development, 65, 138-146.

Knutson, B., Adams, C. M., Fong, G. W., \& Hommer, D. (2001). Anticipation of increasing monetary reward selectively recruits nucleus accumbens. Journal of Neuroscience, 21, RC159.

Kochanska, G. (1997). Multiple pathways to conscience for children with different temperaments: From Toddlerhood to age 5. Developmental Psychology, 33, 228-240.

Kochanska, G. (2001). Emotional development in children with different attachment histories: The first three years. Child Development, 72, 474-490.

Kochanska, G., Murray, K. T., \& Harlan, E. T. (2000). Effortful control in early childhood: Continuity and change, antecedents, and implications for social development. Developmental Psychology, 36, $220-232$.

Kohnstamm, G. A. (1989). Temperament in childhood: Cross-cultural and sex differences. In G. A. Kohnstamm, J. E. Bates, \& M. K. Rothbart (Eds.), Temperament in childhood (pp. 483-508). Oxford, England: Wiley.

Kopp, C. B. (1982). Antecedents of self-regulation: A developmental perspective. Developmental Psychology, 18, 199-214.

Lakatos, K., Nemoda, Z., Birkas, E., Ronai, Z., Kovacs, E., Ney, K., et al. (2003). Association of the D3 dopamine receptor gene and serotonin transporter promoter polymorphisms with infants' response to novelty. Molecular Psychiatry, 8, 90-97.

Lamm, C., Zelazo, P. D., \& Lewis, M. D. (2006). Neural correlates of cognitive control in childhood and adolescence: Disentangling the contributions of age and executive function. Neuropsychologia, 44, 2139-2148.

LeDoux, J. E. (1987). Emotion. In: F. Plum (Ed.), Handbook of physiology. Section 1: The nervous system: Vol. 5. Higher functions of the brain, Part 1. Bethesda, MD: American Psychological Society.

Lemery, K. S., Goldsmith, H. H., Klinnert, M. D., \& Mrazek, D. A. (1999). Developmental Models of infant and childhood temperament. Developmental Psychology, 35, 189-204.

Lengua, L., Wolchik, S., Sandler, I., \& West, S. (2000). The additive and interactive effects of parenting and temperament in predicting adjustment problems of children of divorce. Journal of Clinical Child Psychology, 29, 232-244.

Lozoff, B., Beard, J., Connor, J., Felt, B., Georgieff, M., \& Schallert, T. (2006). Long- lasting neural and behavioral effects of iron deficiency in infancy. Nutrition Reviews, 64, s34-s44.

Lozoff, B., De Andraca, I., Castillo, M., Smith, J., Walter, T., Pino, T., et al. (2003). Behavioral and developmental effects of preventing iron deficiency anemia in healthy full-term infants. Pediatrics, 112, $846-854$.

Lozoff, B., Felt, B. T., Nelson, E. C., Wolf, A. W., Meltzerb, H. W., \& Jimenez, E. (1995). Serum prolactin levels and behavior in infants. Biological Psychiatry, 37, 4-12.

Lozoff, B., Klein, N., Nelson, E., McClish, D., Manuel, M., \& Chacon, M. (1998). Behavior of infants with iron deficiency anemia. Child Development, 69, 24-36.

Luciana, M., \& Nelson, C. A. (1998). The functional emergence of prefrontally-guided working memory systems in four- to eight-year-old children. Neuropsychologia, 36, 273-293.

Luria, A. R. (1966). Higher cortical functions in man. New York: Basic Books.

Marshall, P. J., Bar Haim, Y., \& Fox, N. A. (2002). Development of the EEG from 5 months to 4 years of age. Clinical Neurophysiology, 113, 1199-1208.

Matheny, A. (1991). Play assessment of infant temperament. In C. Schaefer, K. Gitling, \& A. Sandgrund (Eds.), Play diagnosis and assessment. New York: Wiley. 
Matheny, A. P., Jr., \& Phillips, K. (2001). Temperament and context: Correlates of home environment with temperament continuity and change, newborn to 30 months. In T. D. Wachs \& G. A. Kohnstamm (Eds.), Temperament in context (pp. 81-101). Mahwah, NJ: Lawrence Erlbaum.

Matheny, A. P., Riese, M. L., \& Wilson, R. S. (1985). Rudiments of infant temperament: Newborn to 9 months. Developmental Psychology, 21, 486-494.

Mayberg, H. (1997). Limbic-cortical dysregulation: A proposed model of depression. Journal of Neuropsychiatry and Clinical Neuroscience, 9, 471-481.

McClowry, S. G., Hegvik, R. L., \& Teglasi, H. (1993). An examination of the construct validity of the Middle Childhood Temperament Questionnaire. Merrill-Palmer-Quarterly, 39, 279-293.

Mebert, C. J. (1991). Dimensions of subjectivity in parents' ratings of infant temperament. Child Development, 62 , $352-361$.

Metcalfe, J., \& Mischel, W. (1999). A hot/cool system analysis of delay of gratification: Dynamics of willpower. Psychological Review, 106, 3-19.

Moffitt, T. E. (1993). The neuropsychology of conduct disorder. Development and Psychopathology, 5, $135-151$.

Morris, A., Silk, J., Steinberg, L., Sessa, F., Avenevoli, S., \& Essex, M. (2002). Temperamental vulnerability and negative parenting as interacting predictors of child adjustment. Journal of Marriage and Family, 64, 461-471.

Morris, P. L., Robinson, R. G., Raphael, B., \& Hopwood, M. J. (1996). Lesion location and poststroke depression. Journal of Neuropsychiatry and Clinical Neuroscience, 8, 399-403.

Murphy, B. C., Eisenberg, N., Fabes, R. A., Shepard, S., \& Guthrie, I. K. (1999). Consistency and change in children's emotionality and regulation: A longitudinal study. Merrill Palmer Quarterly, 45, 413-444.

Nelson, C. A. (1994). Neural bases of infant temperament. In J. E. Bates \& T. D. Wachs (Eds.), Temperament: Individual differences at the interface of biology and behavior (pp. 47-82). Washington, DC: American Psychological Association.

Nigg, J. T. (2000). On inhibition/disinhibition in developmental psychopathology: Views from cognitive and personality psychology and a working inhibition taxonomy. Psychological Bulletin, 126, 220-246.

Norman, D. A., \& Shallice, T. (1986). Attention to action: Willed and automatic control of behavior. In R. J. Davidson, G. E. Schwartz, \& D. Shapiro (Eds.), Consciousness and self-regulation (pp. 1-18). New York: Plenum Press.

Parasuraman, R., Warm, J. S., \& See, J. E. (1998). Brain systems of vigilance. In R. Parasuraman (Ed.), The attentive brain (pp. 221-256). Cambridge, MA: MIT Press.

Passler, M. A., Isaac, W., \& Hynd, G. W. (1985). Neuropsychological development of behavior attributed to frontal lobe functioning in children. Developmental Neuropsychology, 1, 349-370.

Pedlow, R., Sanson, A., Prior, M., \& Oberklaid, F. (1993). Stability of maternally reported temperament from infancy to 8 years. Developmental Psychology, 29, 998-1007.

Perez-Edgar, K., Roberson-Nay, R., Hardin, M. G., Poeth, K., Guyer, A. E., Nelson, E. E., et al. (2007). Attention alters neural responses to evocative faces in behaviorally inhibited adolescents. NeuroImage, 35 , $1538-1546$.

Pfefferbaum, A., Mathalon, D. H., Sullivan, E. V., Rawles, J. M., Zipursky, R. B., \& Lim, K. O. A. (1994). Quantitative magnetic resonance imaging study of changes in brain morphology from infancy to late adulthood. Archives of Neurology, 51, 874-887.

Pfeifer, M., Goldsmith, H. H., Davidson, R. J., \& Rickman, M. (2002). Continuity and change in inhibited and uninhibited children. Child Development, 73, 1474-1485.

Plomin, R., \& Rutter, M. (1998). Child development, molecular genetics, and what to do with genes once they are found. Child Development, 69, 1223-1242.

Posner, M. I., \& Raichle, M. E. (1994). Images of mind. New York: Scientific American Library/Scientific American Books.

Posner, M. I., \& Rothbart, M. K. (2007). Temperament and learning. Washington, DC: American Psychological Association.

Posner, M. I., \& Rothbart, M. K. (2000). Developing mechanisms of self-regulation. Development and Psychopathology, 12, 427-441.

Posner, M. I., Rothbart, M. K., \& Gerardi-Caulton, G. (2001). Exploring the biology of socialization. In A. R. Damasio, A. Harrington, J. Kagan, B. S. McEwen, H. Moss, \& R. Shaikh (Eds.). Annals of the New York Academy of Sciences: Unity of knowledge: The convergence of natural and human science (Vol. 935, pp. 208-216). New York, NY: New York Academy of Sciences.

Posner, M. I., Rothbart, M. K., \& Sheese, B. E. (2007). Attention genes. Developmental Science, 10, $24-29$. 
Putnam, S., Sanson, A., \& Rothbart, M. (2002). Child Temperament and Parenting (2nd ed.. In M. Bornstein (Ed.). Handbook of parenting (Vol. 1, pp. 255-277). Mahwah NJ: Erlbaum.

Reif, A., \& Lesch, K. (2003). Toward a molecular architecture of personality. Behavioral Brain Research, 139, $1-20$.

Ricciuti, H. N., \& Breitmayer, B. J. (1988). Observational assessments of infant temperament in the natural setting of the newborn nursery: Stability and relationship to perinatal status. Merrill-Palmer-Quarterly, 34, 281-299.

Richards, J. E. (2003). Attention affects the recognition of briefly presented visual stimuli in infants: An ERP study. Developmental Science, 6, 312-328.

Rogeness, G. A., \& McClure, E. B. (1996). Development and neurotransmitter-environmental interactions. Development and Psychopathology, 8, 183-199.

Rothbart, M. K. (1989). Temperament and development. In G. A. Kohnstamm, J. E. Bates, \& M. K. Rothbart (Eds.), Temperament in childhood (pp. 187-247). Oxford, England: Wiley.

Rothbart, M. K. (1991). Temperament: A developmental framework. In J. Strelau \& A. Angleitner (Eds.), Explorations in temperament (pp. 61-64). New York: Plenum.

Rothbart, M. K., Ahadi, S., \& Evans, D. (2000). Temperament and personality: Origins and outcomes. Journal of Personality and Social Psychology, 78, 122-135.

Rothbart, M. K., Ahadi, S. A., \& Hershey, K. L. (1994). Temperament and social behavior in childhood. MerrillPalmer Quarterly, 40, 21-39.

Rothbart, M. K., Ahadi, S. A., Hershey, K. L., \& Fisher, P. (2001). Investigations of temperament at three to seven years: The Children's Behavior Questionnaire. Child Development, 72, 1394-1408.

Rothbart, M. K., \& Bates, J. E. 1998. Temperament. In: Damon, W. (Series Ed.) \& N. Eisenberg (Vol. Ed.), Handbook of child psychology, Vol. 3: Social, emotional, and personality development (5th ed., pp. 105-176). New York: Wiley.

Rothbart, M. K., \& Bates, J. E. (2006). Temperament (6th ed.. In N. Eisenberg, W. Damon, \& R. Lerner (Eds.). Handbook of child psychology: Social, emotional, and personality development (Vol. 3, pp. 99-166). Hoboken, NJ: Wiley.

Rothbart, M. K., \& Derryberry, D. (1981). Development of individual differences in temperament. In M. E. Lamb \& A. L. Brown (Eds.). Advances in developmental psychology (Vol. 1, pp. 37-86). Hillsdale, NJ: Erlbaum.

Rothbart, M. K., Derryberry, D., \& Hershey, K. (2000). Stability of temperament in childhood: Laboratory infant assessment to parent report at seven years. In V. J. Molfese \& D. L. Molfese (Eds.), Temperament and personality development across the life span (pp. 85-119). Mahwah, NJ: Lawrence Erlbaum.

Rothbart, M. K., Derryberry, D., \& Posner, M. I. (1994). A psychobiological approach to the development of temperament. In J. E. Bates \& T. D. Wachs (Eds.), Temperament: Individual differences at the interface of biology and behavior (pp. 83-116). Washington, DC: American Psychological Association.

Rothbart, M. K., Ellis, L. K., Rueda, M. R., \& Posner, M. I. (2003). Developing mechanisms of temperamental effortful control. Journal of Personality, 71, 1113-1143.

Rothbart, M. K., \& Posner, M. (1985). Temperament and the development of self-regulation. In L. C. Hartlage \& C. F. Telzrow (Eds.), The neuropsychology of individual differences: A developmental perspective. New York: Plenum Press.

Rubia, K., Overmeyer, S., Taylor, E., Brammer, M., Williams, S. C. R., Simmons, A., et al. (2000). Functional frontalisation with age: Mapping neurodevelopmental trajectories with fMRI. Neuroscience and Biobehavioral Reviews, 24, 13-19.

Rueda, M. R., Rothbart, M. K., McCandliss, B. D., Saccamanno, L., \& Posner, M. I. (2005). Training, maturation and genetic influences on the development of executive attention. Proceedings of the National Academy of Sciences of the USA, 102, 14931-14936.

Ruff, H. A., \& Rothbart, M. K. (1996). Attention in early development: Themes and variations. New York, NY, US: Oxford University Press.

Sackeim, H. A., Greenberg, M. S., Weiman, A. L., Gur, R. C., Hungerbuhler, J. P., \& Geschwind, N. (1982). Hemispheric asymmetry in the expression of positive and negative emotions. Archives of Neurology, 39, 210-218.

Sanson, A., Prior, M., Garino, E., Oberklaid, F., \& Sewell, J. (1987). The structure of infant temperament. Infant Behavior and Development, 10, 97-104.

Satpute, A. B., \& Lieberman, M. D. (2006). Integrating automatic and controlled processes into neurocognitive models of social cognition. Brain Research, 1079, 86-97. 
Saudino, K. J. (2005). Behavioral genetics and child temperament. Journal of Developmental and Behavioral Pediatrics, 26, 214-223.

Schaul, N. (1998). The fundamental neural mechanisms of electroencephalography. Electroencephalography and Clinical Neurophysiology, 106, 101-107.

Schmidt, L. A., Fox, N. A., Rubin, K. H., \& Sternberg, E. M. (1997). Behavioral and neuroendocrine responses in shy children. Developmental Psychobiology, 30, 127-140.

Schwartz, C. E., Wright, C. I., Shin, L. M., Kagan, J., \& Rauch, S. L. (2003). Inhibited and uninhibited infants "grown up": Adult amygdalar response to novelty. Science, 300, 1952-1953.

Seguin, J. R., Pihl, R. O., Harden, P. W., Tremblay, R. E., \& Boulerice, B. (1995). Cognitive and neuropsychological characteristics of physically aggressive boys. Journal of Abnormal Psychology, 104, 614-624.

Seifer, R., Sameroff, A. J., Barrett, L. C., \& Krafchuk, E. (1994). Infant temperament measured by multiple observations and mother report. Child Development, 65, 1478-1490.

Shaw, P., Greenstein, D., Lerch, J., Clasen, L., Lenroot, R., Gogtay, N., et al. (2006). Intellectual ability and cortical development in children and adolescents. Nature, 440, 676-679.

Sheldon, W. H., \& Stevens, S. S. (1942). The varieties of temperament; a psychology of constitutional differences. Oxford, England: Harper.

Siddappa, A., Georgieff, M., Wewerka, S., Worwa, C., Nelson, C., \& Deregnier, R. (2004). Iron deficiency alters auditory recognition memory in newborn infants of diabetic mothers. Pediatric Research, 55, 1034-1041.

Silberman, E. K., \& Weingartner, H. (1986). Hemispheric lateralization of functions related to emotion. Brain and Cognition, 5, 322-353.

St. James Roberts, I., \& Wolke, D. (1988). Convergences and discrepancies, among mothers' and professionals' assessments of difficult neonatal behaviour. Journal of Child Psychology and Psychiatry, 29, 21-42.

Steinmetz, J. E. (1994). Brain substrates of emotion and temperament. In J. E. Bates \& T. D. Wachs (Eds.), Temperament: Individual differences at the interface of biology and behavior (pp. 17-46). Washington, DC: American Psychological Association.

Stifter, C. A., Spinrad, T. L., \& Braungart-Rieker, J. M. (1999). Toward a developmental model of child compliance: The role of emotion regulation in infancy. Child Development, 70, 21-32.

Strauss, M. E., \& Rourke, D. L. (1978). A multivariate analysis of the Neonatal Behavioral Assessment Scale in several samples. In: A. J. Sameroff (Ed.), Organization and stability of newborn behavior: A commentary on the Brazelton Neonatal Behavior Assessment Scale (pp. 81-91). Monographs of the Society for Research in Child Development (Vol. 43, pp. 5-6, Serial No. 177).

Strelau, J. (1983). Temperament, personality, activity. London: Academic Press.

Strelau, J. (1989). The regulative theory of temperament as a result of East-West influences. In G. A. Kohnstamm, J. E. Bates, \& M. K. Rothbart (Eds.), Temperament in childhood (pp. 35-48). Oxford, England: Wiley.

Strelau, J. (1994). The concepts of arousal and arousability as used in temperament studies. In J. Bates \& T. D. Wachs (Eds.), Temperament: Individual differences at the interface of biology and behavior (pp. 117-142). Washington, DC: American Psychological Association.

Stuss, D. T., \& Benson, D. F. (1984). Neuropsychological studies of the frontal lobes. Psychological Bulletin, 95, $3-28$.

Sutton, S. K., Burnette, C. P., Mundy, P. C., Meyer, J., Vaughan, A., Sanders, C., et al. (2005). Resting cortical brain activity and social behavior in higher functioning children with autism. Journal of Child Psychology and Psychiatry, 46, 211-222.

Sutton, S. K., \& Davidson, R. J. (1997). Prefrontal brain asymmetry: A biological substrate of the behavioral approach and inhibition systems. Psychological Science, 8, 204-210.

Tamura, T., Goldenberg, M., Hou, J., Johnston, K., Cliver, S., Ramey, S., et al. (2002). Cord serum ferritin concentrations and mental and psychomotor development of children at five years of age. Journal of Pediatrics, 140, 165-170.

Thomas, A., \& Chess, S. (1977). Temperament and development. Oxford, England: Brunner/Mazel.

Thomas, A., Chess, S., Birch, H. G., Hertzig, M. E., \& Korn, S. (1963). Behavioral individuality in early childhood. Oxford, England: New York University Press.

Thomas, K. M., Drevets, W. C., Whalen, P. J., Eccard, C. H., Dahl, R. E., Ryan, N. D., et al. (2001). Amygdala response to facial expressions in children and adults. Biological Psychiatry, 49, 309-316.

Tomarken, A. J., Davidson, R. J., \& Henriques, J. B. (1990). Resting frontal brain asymmetry predicts affective responses to films. Journal of Personality and Social Psychology, 59, 791-801. 
Tomarken, A. J., Davidson, R. J., Wheeler, R. E., \& Kinney, L. (1992). Psychometric properties of resting anterior EEG asymmetry: Temporal stability and internal consistency. Psychophysiology, 29, 576-592.

Urry, H. L., van Reekum, C. M., Johnstone, T., Kalin, N. H., Thurow, M. E., Schaefer, H. S., et al. (2006). Amygdala and ventromedial prefrontal cortex are inversely coupled during regulation of negative affect and predict the diurnal pattern of cortisol secretion among older adults. Journal of Neuroscience, 26, 4415-4425.

Vaughn, B. E., Taraldson, B. J., Crichton, L., \& Egeland, B. (1981). The assessment of infant temperament: A critique of the Carey Infant Temperament Questionnaire. Infant Behavior and Development, 4, 1-17.

Vaughn, J., Brown, J., \& Carter, J. (1986). The effects of maternal anemia on infant behavior. Journal of the National Medical Association, 78, 963-968.

Wachs, T. D. (2003). Expanding our view of context: The bio-ecological environment and development. In R. Kail (Ed.). Advances in child development and behavior (Vol. 31, pp. 365-411). San Diego: Academic Press.

Wachs, T. D. (2006). The nature, etiology and consequences of individual differences in temperament. In T. LeMonda \& L. Balter (Eds.), Child psychology: A handbook of contemporary issues (2nd ed., pp. 27-52). New York: Garland.

Wachs, T. D., \& Bates, J. (2001). Temperament. In G. Bremner \& A. Fogel (Eds.), Blackwell handbook of infant development (pp. 465-501). Malden, MA: Blackwell Publishing.

Wachs T. D., Kanishiro, H., \& Gurkas, P. (2006). Temperament and intra-individual variability. Symposium presentation. Occasional temperament conference. Providence Rhode Island.

Wachs, T. D., \& Kohnstamm, G. A. (Eds.). (2001). Temperament in context (pp. 201-222). Mahwah, NJ: Lawrence Erlbaum.

Wachs, T. D., Pollitt, E., Cueto, S., \& Jacoby, E. (2004). Structure and cross-contextual stability of neonatal temperament. Infant Behavior and Development, 27, 382-396.

Wachs, T. D., Pollitt, E., Cueto, S., Jacoby, E., \& Creed-Kanashiro, H. (2005). Relation of neonatal iron status to individual variability in neonatal temperament. Developmental Psychobiology, 46, 141-153.

Whalen, P. J., Bush, G., McNally, R. J., Wilhelm, S., McInerney, S. C., Jenike, M. A., et al. (1998). The emotional counting stroop paradigm: A functional magnetic resonance imaging probe of the anterior cingulate affective division. Biological Psychiatry, 44, 1219-1228.

Wieser, H. G., \& Siegel, A. M. (1993). Relations between the EEG of the cortex, thalamus, and periaquiductal gray in patients suffering from epilepsy and pain syndromes. In S. Zschocke \& E. J. Speckman (Eds.), Basic mechanism of the EEG (pp. 145-182). Boston, MA: Birkhauser.

Wills, T., Sandy, J., Yaeger, A., \& Shiner, O. (2001). Family risk factors and adolescent substance use: Moderation effects for temperament dimensions. Developmental Psychology, 37, 283-297.

Wilson, R. S., \& Matheny, A. P. (1983). Assessment of temperament in infant twins. Developmental Psychology, 19, 172-183. 